\title{
Programa académico de doctorado en gestión pública y gobernabilidad
}

\author{
Mg. Luis Alberto Rubiños Aliaga \\ (ORCID: 0000-0003-3741-3899) \\ dyer_01@hotmail.com \\ Dr. Keller Sánchez Dávila \\ (ORCID: 0000-0003-3911-3806) \\ ksanchezd@ucv.edu.pe \\ Universidad César Vallejo \\ Tarapoto - Perú
}

\section{RESUMEN}

El propósito de estudio fue conocer el plan de incentivo integral como contribuye en la gestión municipal del distrito de Shamboyacu, Provincia de Picota, 2021. El estudio corresponde a una investigación básica, con un diseño de investigación de revisión sistemática, para los procedimientos de recolección de datos se llevó a cabo mediante la búsqueda bibliográfica y sistemática de documentos donde fueron seleccionados artículos científicos en los buscadores de Google Académico, Dialnet, Redalyc, Scielo, EBSCO, los mismos que han sido ordenados en una matriz Excel para facilitar su rápida localización; en total fueron seleccionados 22 artículos. En la técnica de análisis se utilizó la revisión documental y como instrumento se empleó la ficha de recolección de datos luego del análisis de los resultados y las conclusiones obtenidas de acuerdo al objetivo se ha determinado que, durante la revisión de artículos, se encontraron investigaciones tanto cualitativas como cuantitativas, hasta de carácter mixto. El Plan de Incentivos Integral ayuda a la gestión municipal a desarrollarse, pero no es su sola aplicación la que cumplirá con todas las deficiencias que se tienen actualmente, el compromiso de los funcionarios púbicos para el cumplimiento de metas y la permanencia de un buen servicio público será el incentivo para impulsar a que esta gestión pueda llegar al siguiente nivel. Por tanto, se debe mantener un constante interés y estar capacitado para coordinar y cumplir las metas correspondientes al PI con tal de seguir recibiendo este incentivo.

Palabras Clave: plan de incentivo integral, gestión municipal, gasto público, metas. 


\section{Academic doctoral program in public management and governance}

\section{ABSTRACT}

The purpose of the study was to know the comprehensive incentive plan as it contributes to the municipal management of the district of Shamboyacu, Picota Province, 2021. The study corresponds to basic research, with a systematic review research design, for the data collection procedures was carried out by means of the bibliographic and systematic search of documents where scientific articles were selected in the search engines of Academic Google, Dialnet, Redalyc, Scielo, EBSCO, the same ones that have been ordered in an Excel matrix to facilitate its quick localization; in total 22 articles were selected. In the analysis technique the document review was used and as a tool the data collection form was used after the analysis of the results and the conclusions obtained according to the objective has been determined that, during the review of articles, qualitative and quantitative research, even of a mixed nature, was found. The Comprehensive Incentive Plan helps municipal management to develop, but it is not only its implementation that will meet all the current shortcomings, the commitment of public officials to the achievement of goals and the permanence of a good public service will be the incentive to encourage this management to reach the next level. Therefore, there should be continued interest and capacity to coordinate and meet IP targets in order to continue to receive this incentive.

Keywords: comprehensive incentive plan, municipal management, public expenditure, goals. 


\section{INTRODUCCIÓN}

\subsection{Planteamiento del problema}

El municipio distrital de Shaboyacu, es la forma natural de autogobierno que se dan las comunidades que habitan en un territorio preciso. Según la tradición y la práctica latinoamericana, los componentes básicos de la institución municipal son un territorio, una población, una cultura y un gobierno local. Pero el territorio es mucho más que un espacio físico, pues constituye un medio ambiente complejo; la población trasciende la cantidad de habitantes pues se trata de una comunidad con relaciones sociales y políticas dinámicas; en tanto que la cultura representa la acumulación histórica del saber generado por la sociedad local actuando sobre su territorio (Rosales, 2016).

La búsqueda del desarrollo sostenible, requiere trascender la tradicional forma de promover el desarrollo mediante la aplicación de políticas sectoriales. En ese sentido, la dimensión local parece ser la más adecuada para planificar y ejecutar procesos de desarrollo integrales, que permitan integrar efectivamente las dimensiones sociales, económicas y ambientales. Además, la cercanía con la población posibilita la orientación y especificidad a la realidad local (territorialización), mejorando la eficiencia y eficacia de la solución de los problemas (OIT y MDG Achievement Fund, 2017).

El desarrollo local en la actualidad se ha convertido en una apropiada estrategia de desarrollo para territorios sub-nacionales en el marco de la superación de los principales problemas que aquejan a las instituciones públicas locales, su importancia exige al gobierno a plantearse objetivos de superación de estos problemas sociales en un trabajo conjunto y planificando objetivos, lineamientos los cuales deben servir de referencia a los gobierno sub-nacionales para superar las condiciones en que se encuentran los ciudadanos basándose en un conjunto de indicadores no solo económico sino también sociales e institucionales y ambientales (Díaz y Fernández, 2020).

La gestión municipal implica el desarrollo un conjunto de actividades, estrategias y técnicas idóneas que permitan desarrollarse internamente y proyectarse a la comunidad la imagen de un gobierno edil serio, responsable, moderno, eficaz y eficiente a tono con las expectativas de la población, es así que los Instrumentos de Gestión, vienen a ser aquellos documentos en los que se plasman todas las actividades de fortalecimiento y desarrollo Institucional, transparencia en la gestión, desarrollo económico local, servicios municipales, democratización de la gestión, desarrollo humano y promoción social entre otras (García, 2007).

La gestión municipal permite la concertación social como forma política de relación fluida entre Estado y sociedad civil. Donde la cultura del diálogo y el consenso permita crear mecanismos 
y herramientas para la solución de controversias y conflictos sociales. En este sentido, a través de la presente investigación se plantea realizar una revisión sistemática sobre la efectividad de la gestión municipal en el desarrollo local, mediante la exploración de diversos buscadores académicos, los mismos que proporcionaran información fiable y actualizada sobre la temática (Cordero, 2018).

Para comprender la gestión local o municipal, debe partirse de la concepción que toda organización está regida por las normas del estado a nivel constitucional y de las que rigen a los gobiernos locales, sin embargo, para cada uno de ellos, de acuerdo a las especificaciones de gestión deben realizarse a través de instrumentos rectores de la gestión moderna, ante ello, el Proyecto Estratégico Institucional, permite priorizar y ordenar el rumbo de gestión de toda institución pública o privada, pero en el caso de las municipalidades estas deben ser construidas en consenso con todos los actores sociales y gubernamentales de la localidad en la cual se converjan la filosofía y axiología que determine el modelo o característica ya que la visión, misión y de los niveles de valores facilita la interacción entre los agentes y pobladores de la comunidad (Polanco y Caballero, 2020).

En la gestión pública en el Perú, lo que al ciudadano le importa es que los servicios le lleguen de la mejor manera. Para ello se requiere mejorar la gestión, se requiere de coordinación y articulación de las políticas públicas con otros sectores y niveles de gobierno. Se complica aún más si el planeamiento municipal en los países latinoamericanos se deja a expensas de los recursos económicos, la falta de capacitación, ausencia de profesionales especializados, la escasa información para el desarrollo de planes, así como de la incorrecta decisión política y técnica, la improvisación, el clientelismo, la cultura de la corrupción y los apetitos siguen entrampando el desarrollo y bienestar de la población (Hurtado, y Gonzales, 2015).

Una vez entendido de qué se trata la gestión municipal, se debe comprender qué es el Plan de Incentivos y cómo este es aplicado en las municipalidades locales: El PI forma parte de un esfuerzo para mejorar la calidad de los servicios públicos locales que están vinculados a Programas Presupuestales articulados territorialmente y mejorar la sostenibilidad financiera local mediante el incremento en la recaudación de tributos municipales.

Este busca, en líneas generales, una mejora en la calidad de los servicios que recibe la población o una mejora de la gestión municipal promoviendo mayor eficiencia en la recaudación y/o ejecución de recursos. Existe un vínculo entre la entrega de servicios a la población y la recaudación bajo la lógica del equilibrio presupuestal, la cual indica que debe haber una correspondencia entre los ingresos generados y los recursos que se asignan. Bajo esta premisa, es necesario garantizar una continuidad en la generación de recursos, apuntando a una mejora 
constante, para asegurar la presencia de los recursos necesarios para la entrega de servicios públicos de calidad a la población (MEF, 2018).

Al implicar una transferencia de recursos a las municipalidades, solo podrá hacerse si se realiza el cumplimiento de metas en un periodo determinado. Dichas metas son formuladas por diversas entidades públicas del gobierno central y tienen como objetivo impulsar resultados cuyo logro requiere un trabajo articulado y coordinado con las municipalidades. El Plan de Incentivos está diseñado para que participen todas las municipalidades sin necesidad de postular o de presentar algún formulario o requisito previo. Las municipalidades se incorporan automáticamente cuando presentan el cumplimiento de la(s) meta(s).

Entonces, este plan, invita a las municipalidades a mejorar su gestión incluso antes de obtener el beneficio. Una vez se cumplen las metas que se establecen según el tipo de municipalidad que sea, se le hará la transferencia para mejorar mucho más la gestión municipal ejecutada. Las asignaciones de recursos por el cumplimiento de metas evaluadas serán de uso exclusivo para lograr los objetivos propuestos por Plan de Incentivos, a través del sostenimiento de metas y cumplimiento de las mismas. Este procedimiento se desarrollará a través de la ejecución de actividades o proyectos (Escobedo, 2019).

Es necesario indicar que, en el marco del PI y la propuesta de progresividad de las metas, se sugiere que las municipalidades utilicen al menos una fracción de las transferencias para garantizar el cumplimiento de las metas en los siguientes años, de esta forma se podrá generar un "círculo virtuoso" que garantice continuidad en la obtención de los incentivos, en la medida que se programan y ejecutan recursos adicionales que permitan el cumplimiento de las metas (MEF, 2018).

\subsection{Formulación del problema}

¿De qué manera el plan de incentivo integral contribuye en la gestión municipal del distrito de Shamboyacu, provincia de Picota, 2021 ?

\subsection{Objetivo}

Conocer el plan de incentivo integral como contribuye en la gestión municipal del distrito de Shamboyacu, provincia de Picota, 2021.

\section{MATERIALES Y MÉTODOS}

\subsection{Diseño de estudio}

El presente estudio corresponde al tipo básico, la cual se caracteriza por la inexistencia de manipulación de variables, enfocándose en la descripción de los hechos y fenómenos en su estado natural (Hernández, et al., 2014).

El diseño de estudio es la revisión sistemática; reúne toda la evidencia empírica que responde 
criterios de elegibilidad previamente establecidos, para responder una pregunta específica de investigación. Utiliza métodos sistemáticos y explícitos, que se eligen con el fin de minimizar y eliminar sesgos, brindando así resultados confiables a partir de los cuales se puedan extraer conclusiones y tomar decisiones (Arévalo, Ortuño y Arévalo, 2010).

\subsection{Procedimiento de recolección de datos}

Se efectuó la búsqueda bibliográfica y sistemática de artículos científicos en las siguientes bases de datos: Google Académico, Dialnet, Redalyc, Scielo, EBSCO (en el orden que se indica). La búsqueda y selección de los artículos inició en el período 2017 hasta el año 2021. La manera de cómo se procedió para la selección de los artículos siguió una estructura organizada, que consistió en primer lugar en elegirlos en función de la revisión del título, del resumen, así como las palabras utilizadas para la búsqueda del artículo, para verificar si guardan congruencia con los criterios de inclusión establecidos.

Las palabras que fueron utilizadas para la búsqueda se colocaron de acuerdo al idioma que permitía específicamente cada una de las bases de datos y luego se hizo el filtro de los resultados según el período de tiempo. Las palabras o términos utilizados para la búsqueda fueron las siguientes: "gestión municipal” / "desarrollo local” / "municipal management"/ "Incentivos"/ "local government"/"plan de incentivos"/'local management"/"Presupuesto por resultados"/"Gestión de resultados"/. En segundo lugar, se procedió a leer los artículos seleccionados, que cumplían los criterios de inclusión.

Se obtuvo 71 artículos de texto completo que fueron estimados para analizar su elegibilidad. Excluyendo aquellos artículos cuyo tema trataba sobre gestión municipal y plan de incentivos. Como resultado de lo anteriormente expuesto se quedó con 22 artículos.

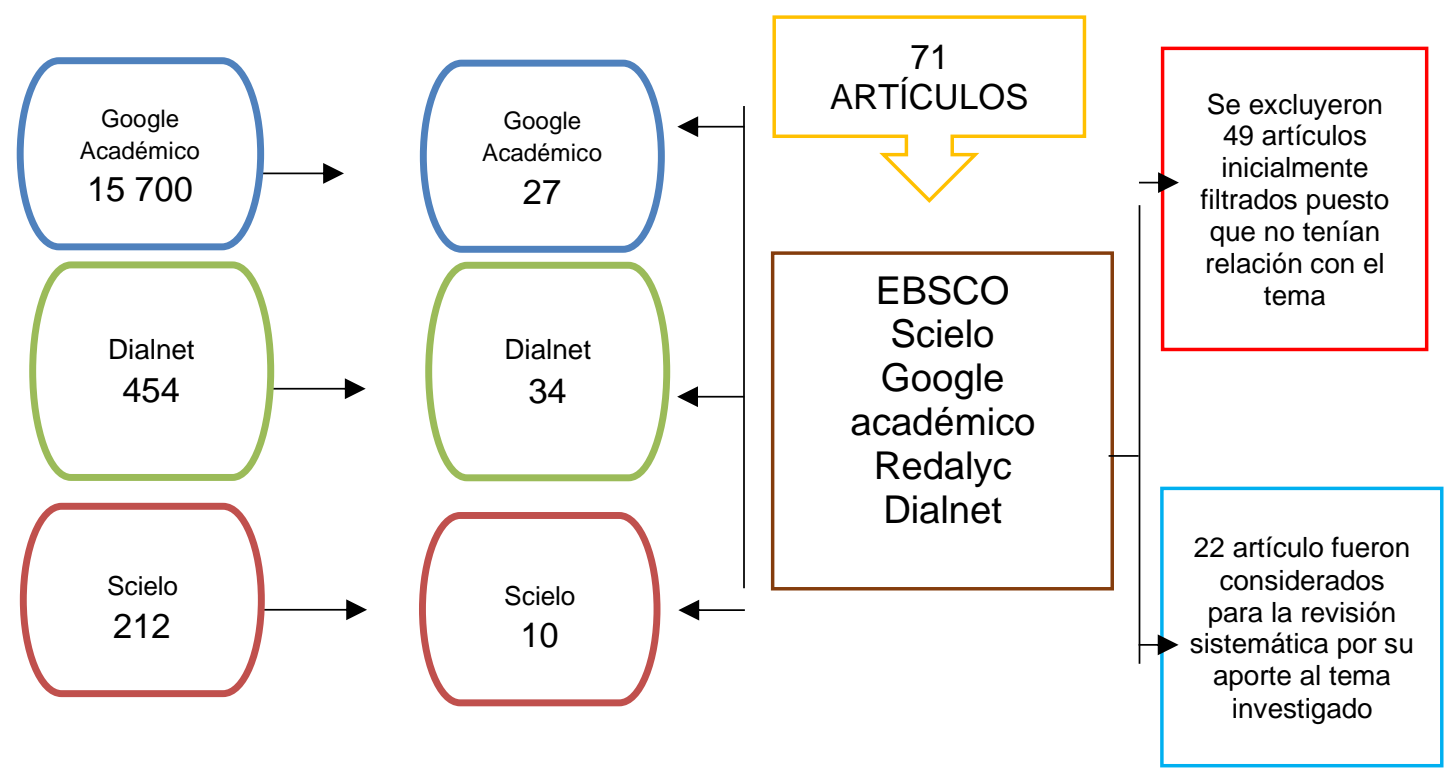




\section{Criterios de inclusión}

- Los criterios de inclusión para la determinación de los artículos para la presente revisión sistemática y en función del interés planteado, consistieron en: estudios publicados entre enero del 2017 y mayo del 2021. Asimismo, que dichos estudios aborden variables que se correlacionen con gestión municipal y desarrollo local.

- Que los estudios hayan sido publicados en inglés o español.

\section{Criterios de exclusión}

- Se excluyeron los artículos que no fuesen de carácter científico o que sus textos estén incompletos. Asimismo, no se consideraron aquellos artículos que hayan tenido como propósito principal, la validación de un instrumento de medición o que sean revisiones sistemáticas o que sean estudios exclusivamente cualitativos.

\subsection{Técnica de análisis}

- En el presente trabajo de investigación se utilizó la técnica de revisión documental, la cual se manejó para revisar investigaciones referentes a la degradación de polímeros por biotecnologías bacterianas permitiendo un mejor recojo de datos.

- Como instrumento se utilizó fichas de recolección de datos de artículos científicos lo cual nos permitió un registro de base de datos de investigaciones, este instrumento es de suma importancia ya que facilita el acceso a la información que se necesita para la resolución del problema.

- La revisión documental consideró artículos de investigación en el ámbito internacional y nacional, cuya prioridad gestión municipal y plan de incentivos municipales. Se consideró pertinente la inclusión de los artículos más importantes, según la evidencia que presentaron, excluyéndose los que no cumplieron con los criterios establecidos. 


\section{RESULTADOS}

1.1. Tabla 1. Estudios revisados sobre gestión municipal

\begin{tabular}{|c|c|c|c|c|}
\hline \multicolumn{5}{|c|}{ DATOS DE LA PUBLICACIÓN } \\
\hline 1. Autor & Año & Nombre de la Investigación & $\begin{array}{c}\text { Revista donde su ubica la } \\
\text { publicación }\end{array}$ & $\begin{array}{c}\text { Volumen y } \\
\text { número }\end{array}$ \\
\hline $\begin{array}{l}\text { Gómez-Álvarez, } \\
\text { R., Morales, R., y } \\
\text { Rodríguez, C. }\end{array}$ & 2017 & La Economía del Bien Común en el ámbito local & $\begin{array}{c}\text { https://www.redalyc.org/pdf/174/174 } \\
\text { 52685007.pdf } \\
\text { CIRIEC-España, Revista de } \\
\text { Economía Pública, Social y } \\
\text { Cooperativa }\end{array}$ & $1(90)$ \\
\hline
\end{tabular}

\section{CONTENIDO DE LA PUBLICACIÓN}

\begin{tabular}{|c|c|c|c|c|c|}
\hline $\begin{array}{c}\text { Tipo y Diseño de } \\
\text { Investigación }\end{array}$ & $\begin{array}{c}\text { Población y } \\
\text { Muestra }\end{array}$ & Instrumentos & $\begin{array}{c}\text { Aspectos } \\
\text { éticos }\end{array}$ & Resultados & Conclusión \\
\hline $\begin{array}{l}\text { Cualitativa } \\
\text { Descriptiva } \\
\text { simple }\end{array}$ & $\begin{array}{l}\text { Funcionarios } \\
\text { públicos españoles }\end{array}$ & $\begin{array}{l}\text { Encuesta de } \\
\text { Balance de } \\
\text { Bien Común }\end{array}$ & Ninguno & $\begin{array}{l}\text { La transformación de un municipio hacia } \\
\text { el bien común requiere sobre todo de } \\
\text { motivación intrínseca por parte de las } \\
\text { personas y colectivos que lo integran, pero } \\
\text { desde un ayuntamiento se pueden generar } \\
\text { incentivos adicionales para motivar las } \\
\text { buenas prácticas.. }\end{array}$ & $\begin{array}{l}\text { En cuanto a la gestión pública, } \\
\text { debe estar orientada hacia el } \\
\text { Bien Común, entendido como } \\
\text { la promoción de los valores } \\
\text { humanos de la dignidad } \\
\text { humana, solidaridad, } \\
\text { sostenibilidad, justicia social y } \\
\text { la democracia y transparencia. } \\
\text { variables y dimensiones de } \\
\text { gestión que permitan } \\
\text { escudriñar con mayor énfasis } \\
\text { en la problemática que } \\
\text { aquejan los gobiernos locales. }\end{array}$ \\
\hline
\end{tabular}




\begin{tabular}{|c|c|c|c|c|}
\hline \multicolumn{5}{|c|}{ DATOS DE LA PUBLICACIÓN } \\
\hline 2. Autor & Año & Nombre de la Investigación & $\begin{array}{c}\text { Revista donde su ubica la } \\
\text { publicación }\end{array}$ & $\begin{array}{l}\text { Volumen y } \\
\text { número }\end{array}$ \\
\hline $\begin{array}{l}\text { Anastacio, C.A. } \\
\text { García, A. J., y } \\
\text { Mego, O. }\end{array}$ & 2019 & $\begin{array}{c}\text { Gestión del talento humano por competencias y su relación } \\
\text { con la motivación de los colaboradores de una } \\
\text { municipalidad de la región de Lambayeque, Perú, } 2019\end{array}$ & $\frac{h t t p: / / \text { revistas.uss.edu.pe/index.php/t }}{\frac{\text { zh/article/view/1394/1928 }}{\text { Revista Tzhoecoe }}}$ & $4(12)$ \\
\hline
\end{tabular}

CONTENIDO DE LA PUBLICACIÓN

\begin{tabular}{|c|c|c|c|c|c|}
\hline $\begin{array}{c}\text { Tipo y Diseño de } \\
\text { Investigación }\end{array}$ & $\begin{array}{c}\text { Población y } \\
\text { Muestra } \\
\end{array}$ & Instrumentos & $\begin{array}{c}\text { Aspectos } \\
\text { éticos } \\
\end{array}$ & Resultados & Conclusión \\
\hline Cuantitativo & $\begin{array}{l}165 \text { colaboradores } \\
\text { de la Municipalidad } \\
\text { de Lambayeque, } \\
\text { Perú }\end{array}$ & Cuestionario & Ninguno & $\begin{array}{l}\text { A través de esta investigación se reafirma } \\
\text { que se deben generar políticas de } \\
\text { promoción y ascensos, acompañado de } \\
\text { programas de desarrollo de personal a } \\
\text { corto y mediano plazo, generando cuadros } \\
\text { laborales debidamente capacitados, que le } \\
\text { permita actualizar e incrementar sus } \\
\text { capacidades laborales de los trabajadores. }\end{array}$ & $\begin{array}{l}\text { La variable motivación } \\
\text { laboral, a nivel de la } \\
\text { dimensión, desarrollo de } \\
\text { personal, línea de carrera y } \\
\text { aprendizaje, tienen una } \\
\text { relación significativa de } \\
0,816 \text {, donde la motivación } \\
\text { tienen una incidencia directa } \\
\text { con el desarrollo y aprendizaje } \\
\text { laboral Respecto a las } \\
\text { variables gestión del talento } \\
\text { humano y la motivación } \\
\text { laboral, tienen una relación } \\
\text { significativamente alta de } \\
\text { (r = 0.816; p<0.001), quiere } \\
\text { decir que la gestión del talento } \\
\text { humano, se asocia } \\
\text { directamente con la } \\
\text { motivación laboral. }\end{array}$ \\
\hline
\end{tabular}




\begin{tabular}{|c|c|c|c|c|}
\hline \multicolumn{5}{|c|}{ DATOS DE LA PUBLICACIÓN } \\
\hline 3. Autor & Año & Nombre de la Investigación & $\begin{array}{l}\text { Revista donde su ubica la } \\
\text { publicación }\end{array}$ & $\begin{array}{l}\text { Volumen y } \\
\text { número }\end{array}$ \\
\hline $\begin{array}{l}\text { Vargas, J.A. y } \\
\text { Zavaleta, W.E. }\end{array}$ & 2020 & $\begin{array}{l}\text { La gestión del presupuesto por resultados y la calidad del } \\
\text { gasto en gobiernos locales }\end{array}$ & 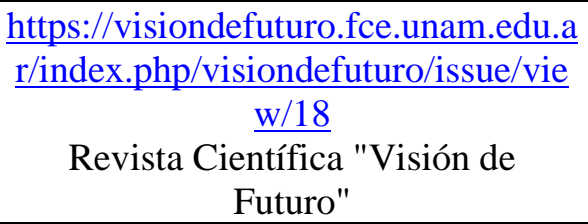 & $2(24)$ \\
\hline
\end{tabular}

\section{CONTENIDO DE LA PUBLICACIÓN}

\begin{tabular}{|c|c|c|c|c|c|}
\hline $\begin{array}{l}\text { Tipo y Diseño de } \\
\text { Investigación }\end{array}$ & $\begin{array}{l}\text { Población y } \\
\text { Muestra }\end{array}$ & Instrumentos & $\begin{array}{l}\text { Aspectos } \\
\text { éticos }\end{array}$ & Resultados & Conclusión \\
\hline Cuantitativo & $\begin{array}{l}83 \text { distritos de } \mathrm{La} \\
\text { Libertad }\end{array}$ & Censo & Ninguno & $\begin{array}{l}\text { La gestión debe enfocarse hacia una nueva } \\
\text { perspectiva centrada en resultados, donde } \\
\text { el presupuesto por resultados resulta su } \\
\text { herramienta clave, y en nuestro país se } \\
\text { viene implementando con cuatro } \\
\text { instrumentos, los programas } \\
\text { presupuestales, el seguimiento, las } \\
\text { evaluaciones independientes y los } \\
\text { incentivos a la gestión. El aporte de la } \\
\text { presente investigación radica en estudiar la } \\
\text { forma cómo los gobiernos locales utilizan } \\
\text { los recursos públicos, para ello se propone } \\
\text { analizar el funcionamiento del Presupuesto } \\
\text { por Resultados y evaluar la calidad del } \\
\text { gasto público que realizan las } \\
\text { municipalidades }\end{array}$ & $\begin{array}{l}\text { Estos resultados hallan eco } \\
\text { con los hallados por Mejía } \\
\text { (2014) quien obtiene que el } \\
\text { Presupuesto por Resultados } \\
\text { como herramienta si influye } \\
\text { en la mejora de la Gestión } \\
\text { Gerencial de un gobierno local } \\
\text { que dicho investigador } \\
\text { analizó, porque parte de una } \\
\text { visión integrada de } \\
\text { planificación y articulación } \\
\text { que busca acciones articuladas } \\
\text { en función a la resolución de } \\
\text { los problemas críticos que } \\
\text { afectan a la población, los } \\
\text { mismos que se han } \\
\text { comprobado en este estudio. }\end{array}$ \\
\hline
\end{tabular}




\begin{tabular}{|c|c|c|c|c|c|}
\hline \multicolumn{6}{|c|}{ DATOS DE LA PUBLICACIÓN } \\
\hline 4. Autor & Año & \multicolumn{3}{|c|}{ Nombre de la Investigación } & $\begin{array}{c}\text { Revista donde su ubica la } \\
\text { publicación }\end{array}$ \\
\hline Jiménez, W. & $\begin{array}{r}\text { Movili } \\
\text { camb }\end{array}$ & \multicolumn{3}{|c|}{$\begin{array}{c}\text { Movilización de recursos domésticos, desarrollo social y } \\
\text { cambio institucional: Descentralización y autonomías } \\
\text { municipales en Bolivia }\end{array}$} & $\begin{array}{l}\text { stor.eu/bitstream/1 } \\
\frac{1010303007 . p d f}{\text { orking Paper }}\end{array}$ \\
\hline \multicolumn{6}{|c|}{ CONTENIDO DE LA PUBLICACIÓN } \\
\hline $\begin{array}{l}\text { Tipo y Diseño de } \\
\text { Investigación }\end{array}$ & $\begin{array}{c}\text { Población y } \\
\text { Muestra }\end{array}$ & Instrumentos & $\begin{array}{c}\text { Aspectos } \\
\text { éticos } \\
\end{array}$ & Resultados & Conclusión \\
\hline Cuantitativo & $\begin{array}{l}339 \text { municipios } \\
\text { Bolivianos }\end{array}$ & $\begin{array}{l}\text { Análisis } \\
\text { bibliográfico }\end{array}$ & Ninguno & $\begin{array}{l}\text { las brechas sociales entre municipios } \\
\text { siguen siendo profundas y se explican, } \\
\text { en parte, por la debilidad de la gestión } \\
\text { pública, falta de incentivos para } \\
\text { obtener recursos propios y } \\
\text { desarticulación de la gestión local en } \\
\text { la provisión de servicios públicos. A } \\
\text { pesar del aumento de excedentes de } \\
\text { recursos naturales desde mediados de } \\
\text { los años } 2000 \text { que propiciaron un } \\
\text { incremento de las transferencias } \\
\text { intergubernamentales, los gobiernos } \\
\text { municipales aún no se consolidaron y } \\
\text { todavía se observan deficiencias en el } \\
\text { modelo fiscal-financiero para atender } \\
\text { necesidades del desarrollo local. }\end{array}$ & $\begin{array}{l}\text { La agenda para el desarrollo local aún } \\
\text { está pendiente, se requiere fortalecer a } \\
\text { los gobiernos municipales, } \\
\text { especialmente a aquellos que quedan } \\
\text { alejados de zonas metropolitanas y } \\
\text { presentan menor capacidad para } \\
\text { ejecutar e impulsar proyectos de } \\
\text { desarrollo social. La función que realiza } \\
\text { el nivel central a través del Servicio } \\
\text { Estatal de Autonomías es valorable, } \\
\text { pero se requiere un mayor impulso al } \\
\text { uso de herramientas y modernización } \\
\text { de la gestión pública. Al mismo tiempo, } \\
\text { el apoyo a la gobernabilidad municipal } \\
\text { es esencial para llevar adelante } \\
\text { programas de desarrollo social. }\end{array}$ \\
\hline
\end{tabular}




\begin{tabular}{|c|c|c|c|c|}
\hline \multicolumn{5}{|c|}{ DATOS DE LA PUBLICACIÓN } \\
\hline 5. Autor & Año & Nombre de la Investigación & $\begin{array}{c}\text { Revista donde su ubica la } \\
\text { publicación }\end{array}$ & $\begin{array}{l}\text { Volumen y } \\
\text { número }\end{array}$ \\
\hline $\begin{array}{l}\text { Seminario, F. y } \\
\text { Delgado, J.M. }\end{array}$ & 2020 & $\begin{array}{l}\text { Evaluación según modernización del Estado en la gestión } \\
\text { municipal, } 2020\end{array}$ & $\begin{array}{c}\text { https://ciencialatina.org/index.php/ci } \\
\text { enciala/article/view/131/112 } \\
\text { Ciencia Latina Revista Científica } \\
\text { Multidisciplinar }\end{array}$ & $2(4)$ \\
\hline
\end{tabular}

\begin{tabular}{|c|c|c|c|}
\hline \multicolumn{4}{|c|}{ CONTENIDO DI } \\
\hline $\begin{array}{l}\text { Tipo y Diseño de } \\
\text { Investigación }\end{array}$ & $\begin{array}{c}\text { Población y } \\
\text { Muestra }\end{array}$ & Instrumentos & $\begin{array}{l}\text { Aspectos } \\
\text { éticos }\end{array}$ \\
\hline $\begin{array}{l}\text { Cualitativa } \\
\text { Descriptiva }\end{array}$ & $\begin{array}{lr}10 \text { artículos } & \text { sobre } \\
\text { desarrollo } & \text { de } \\
\text { gestión pública }\end{array}$ & $\begin{array}{l}\text { Revisión } \\
\text { bibliográfica }\end{array}$ & Ninguno \\
\hline
\end{tabular}




\begin{tabular}{|c|c|c|c|c|c|}
\hline \multicolumn{6}{|c|}{ DATOS DE LA PUBLICACIÓN } \\
\hline 6. Autor & $\overline{\text { Año }}$ & \multicolumn{2}{|c|}{ Nombre de la Investigación } & \multicolumn{2}{|c|}{$\begin{array}{c}\text { Revista donde su ubica la } \\
\text { publicación }\end{array}$} \\
\hline Tejada, R. & Incenti & \multicolumn{2}{|c|}{$\begin{array}{l}\text { intrínsecos al servidor público para una gestión } \\
\text { por resultados eficiente }\end{array}$} & $\begin{array}{r}\text { http://revista.enap.edu. } \\
\frac{\text { w/4466/503 }}{\text { Saber Serv }}\end{array}$ & $\begin{array}{l}\mathrm{pe} / \text { article/vie } \\
\frac{3}{\mathrm{ir}}\end{array}$ \\
\hline \multicolumn{6}{|c|}{ CONTENIDO DE LA PUBLICACIÓN } \\
\hline $\begin{array}{l}\text { Tipo y Diseño de } \\
\text { Investigación }\end{array}$ & $\begin{array}{l}\text { Población y } \\
\text { Muestra }\end{array}$ & Instrumentos & $\begin{array}{l}\text { Aspectos } \\
\text { éticos }\end{array}$ & Resultados & Conclusión \\
\hline Cuantitativo & $\begin{array}{l}\text { Servidores públicos } \\
\text { peruanos }\end{array}$ & $\begin{array}{l}\text { Análisis } \\
\text { bibliográfico }\end{array}$ & Ninguno & $\begin{array}{l}\text { Demuestra que un modelo de gestión } \\
\text { eficiente y eficaz del servicio público exige } \\
\text { diseñar algún tipo de sistema o mecanismo } \\
\text { en base a motivaciones y preferencia } \\
\text { intrínsecos. Es decir, en la medida que se } \\
\text { obtienen resultados se otorgan beneficios o } \\
\text { recompensas por el logro. La } \\
\text { implementación de la gestión del } \\
\text { rendimiento desarrollada por el Servir, que } \\
\text { establece indicadores, metas y un } \\
\text { mecanismo de evaluación individual, es } \\
\text { una adecuada plataforma para diseñar un } \\
\text { sistema de incentivos }\end{array}$ & $\begin{array}{l}\text { Un modelo de gestión } \\
\text { eficiente y eficaz del servicio } \\
\text { público exige diseñar algún } \\
\text { tipo de sistema o mecanismo } \\
\text { en base a motivaciones y } \\
\text { preferencia intrínsecos. Es } \\
\text { decir, en la medida que se } \\
\text { obtienen resultados se otorgan } \\
\text { beneficios o recompensas por } \\
\text { el logro. La implementación } \\
\text { de la gestión del rendimiento } \\
\text { desarrollada por el Servir, que } \\
\text { establece indicadores, metas y } \\
\text { un mecanismo de evaluación } \\
\text { individual, es una adecuada } \\
\text { plataforma para diseñar un } \\
\text { sistema de incentivos }\end{array}$ \\
\hline
\end{tabular}




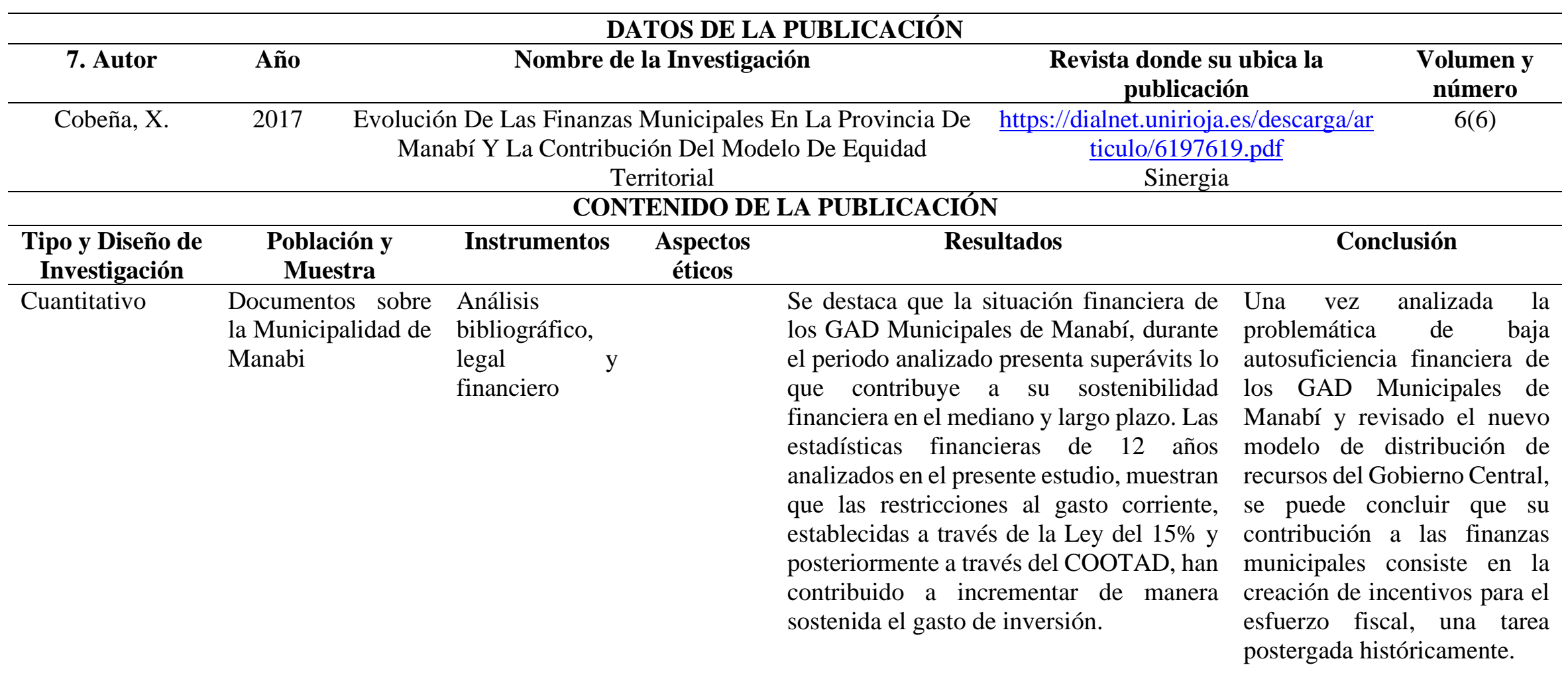


Tabla 2: Estudios realizados sobre plan de incentivos

\begin{tabular}{cccc}
\hline & & \multicolumn{2}{c}{ DATOS DE LA PUBLICACIÓN } \\
\hline 8. Autor & Año & Nombre de la Investigación & $\begin{array}{c}\text { Revista donde su ubica la } \\
\text { publicación }\end{array}$ \\
\hline $\begin{array}{c}\text { Pared, A. y Zelaya, } \\
\text { M. }\end{array}$ & 2020 & $\begin{array}{c}\text { La innovación y el desarrollo local en el gobierno municipal } \\
\text { hacia un estado de situación actual en Argentina }\end{array}$ & $\begin{array}{c}\text { https://publicaciones.unpaz.edu.ar/O } \\
\text { JS/index.php/ec/article/view/723/669 }\end{array}$ \\
\hline
\end{tabular}

CONTENIDO DE LA PUBLICACIÓN

\begin{tabular}{|c|c|c|c|c|c|}
\hline $\begin{array}{l}\text { Tipo y Diseño de } \\
\text { Investigación }\end{array}$ & $\begin{array}{c}\text { Población y } \\
\text { Muestra }\end{array}$ & Instrumentos & $\begin{array}{c}\text { Aspectos } \\
\text { éticos }\end{array}$ & Resultados & Conclusión \\
\hline Cualitativa & $\begin{array}{l}\text { Documentación } \\
\text { acerca de las } \\
\text { Municipalidades } \\
\text { Argentinas }\end{array}$ & $\begin{array}{l}\text { Análisis } \\
\text { bibliográfico, } \\
\text { legal } \\
\text { financiero }\end{array}$ & y - & $\begin{array}{l}\text { Se ha tornado imprescindible la aplicación } \\
\text { de herramientas de modernización en los } \\
\text { municipios argentinos que hacen } \\
\text { referencia a dos grandes líneas estratégicas } \\
\text { de gestión: las transformaciones } \\
\text { institucionales, que implican llevar a cabo } \\
\text { cambios orientados a incrementar la } \\
\text { productividad y mejorar la calidad de los } \\
\text { servicios prestados, involucrando por igual } \\
\text { a los empleados públicos y a ciudadanos, y } \\
\text { las transformaciones transversales, } \\
\text { destinadas a optimizar y consolidar los } \\
\text { sistemas horizontales (que incluye la } \\
\text { gestión del capital humano, los sistemas de } \\
\text { compras y contrataciones y de } \\
\text { administración financiera, y el gobierno } \\
\text { electrónico). }\end{array}$ & $\begin{array}{l}\text { La reforma del Estado dio a los gobiernos } \\
\text { locales nuevas competencias, sumando de } \\
\text { esta forma áreas de gestión que los forzaron a } \\
\text { reestructurar sus funciones y competencias. } \\
\text { El incremento de la agenda política municipal } \\
\text { torna imprescindible la innovación en su } \\
\text { gestión, si se considera a las innovaciones } \\
\text { como el resultado de recombinaciones de } \\
\text { elementos ya conocidos o de nuevos usos o de } \\
\text { la creatividad puesta al servicio de la } \\
\text { producción institucional para marcar una } \\
\text { diferencia }\end{array}$ \\
\hline
\end{tabular}




\begin{tabular}{|c|c|c|c|c|c|}
\hline \multicolumn{6}{|c|}{ DATOS DE LA PUBLICACIÓN } \\
\hline 9. Autor & $\overline{\text { Año }}$ & \multicolumn{3}{|c|}{ Nombre de la Investigación } & $\begin{array}{l}\text { Revista donde su ubica la } \\
\text { publicación }\end{array}$ \\
\hline Papazoglou, G. & So & \multicolumn{3}{|c|}{$\begin{array}{l}\text { Sociedad y cultura: políticas culturales impulsadas por las } \\
\text { autoridades locales como factor de desarrollo local: el } \\
\text { ejemplo del municipio de Xanthi-Grecia }\end{array}$} & $\frac{\text { https://www.mdpi.com/2571- }}{\frac{9408 / 2 / 3 / 161 / \mathrm{htm}}{\text { Heritage }}}$ \\
\hline \multicolumn{6}{|c|}{ CONTENIDO DE LA PUBLICACIÓN } \\
\hline $\begin{array}{l}\text { Tipo y Diseño de } \\
\text { Investigación }\end{array}$ & $\begin{array}{c}\text { Población y } \\
\text { Muestra }\end{array}$ & Instrumentos & $\begin{array}{l}\text { Aspectos } \\
\text { éticos }\end{array}$ & Resultados & Conclusión \\
\hline Cualitativa & $\begin{array}{l}\text { Municipalidad } \\
\text { Xanthi-Grecia }\end{array}$ & $\begin{array}{l}\text { Investigación } \\
\text { empírica } \\
\text { realizada en la } \\
\text { ciudad }\end{array}$ & & $\begin{array}{l}\text { El desarrollo cultural también tiene como } \\
\text { objetivo el desarrollo local sostenible: el } \\
\text { atractivo de la ciudad. Por lo tanto, el } \\
\text { municipio puede ser el lugar de encuentro } \\
\text { de todos los esfuerzos para promover el } \\
\text { desarrollo social y el progreso a nivel local } \\
\text { y regional, siempre que exista un marco } \\
\text { institucional adecuado para la ejecución de } \\
\text { proyectos culturales descentralizados y } \\
\text { acciones similares que conduzcan a su vez } \\
\text { a los correspondientes beneficios } \\
\text { socioeconómicos, y que también puedan } \\
\text { actuar como antídoto a la crisis y en el } \\
\text { mejoramiento del gobierno municipal. }\end{array}$ & $\begin{array}{l}\text { El desarrollo de la cultura es un } \\
\text { instrumento importante para alcanzar } \\
\text { el objetivo del desarrollo local: la } \\
\text { aplicación de una política cultural } \\
\text { estatal coherente y organizada, basada } \\
\text { en la experiencia europea. En lo que } \\
\text { respecta al presente documento, } \\
\text { podría desencadenar un proceso } \\
\text { fecundo y constructivo de reflexión } \\
\text { sobre el papel de la política cultural } \\
\text { local en la consecución del desarrollo } \\
\text { social y regional. Las cuestiones que } \\
\text { aquí se plantean pueden contribuir } \\
\text { tanto a la investigación científica } \\
\text { como al diálogo, y también destacar el } \\
\text { papel de los municipios como activos } \\
\text { culturales activos con identidades } \\
\text { culturales distintas en el contexto de } \\
\text { una Europa de regiones. }\end{array}$ \\
\hline
\end{tabular}

Ciencia Latina Revista Científica Multidisciplinar, Ciudad de México, México. 


\begin{tabular}{|c|c|c|c|}
\hline \multicolumn{4}{|c|}{ DATOS DE LA PUBLICACIÓN } \\
\hline 10. Autor & Año & Nombre de la Investigación & Revista donde su ubica la publicación \\
\hline Delgado, J. & 2020 & $\begin{array}{l}\text { Mejora de los servicios públicos en el } \\
\text { fortalecimiento de la gestión municipal }\end{array}$ & $\begin{array}{c}\text { https://www.ciencialatina.org/index.php/ciencia } \\
\underline{\text { la/article/view/151/182 }} \\
\text { Ciencia Latina Revista Científica } \\
\text { Multidisciplinar }\end{array}$ \\
\hline \multicolumn{4}{|c|}{ CONTENIDO DE LA PUBLICACIÓN } \\
\hline $\begin{array}{c}\text { Tipo y Diseño } \\
\text { de } \\
\text { Investigación } \\
\end{array}$ & $\begin{array}{l}\text { Población y } \\
\text { Muestra }\end{array}$ & Aspectos éticos & Conclusión \\
\hline Cualitativa & $\begin{array}{l}\text { Documentos } \\
\text { sobre la } \\
\text { Municipalidad } \\
\text { de Tarapoto- } \\
\text { Perú }\end{array}$ & $\begin{array}{l}\text { Material } \\
\text { bibliográfico } \\
\text { primario }\end{array}$ & 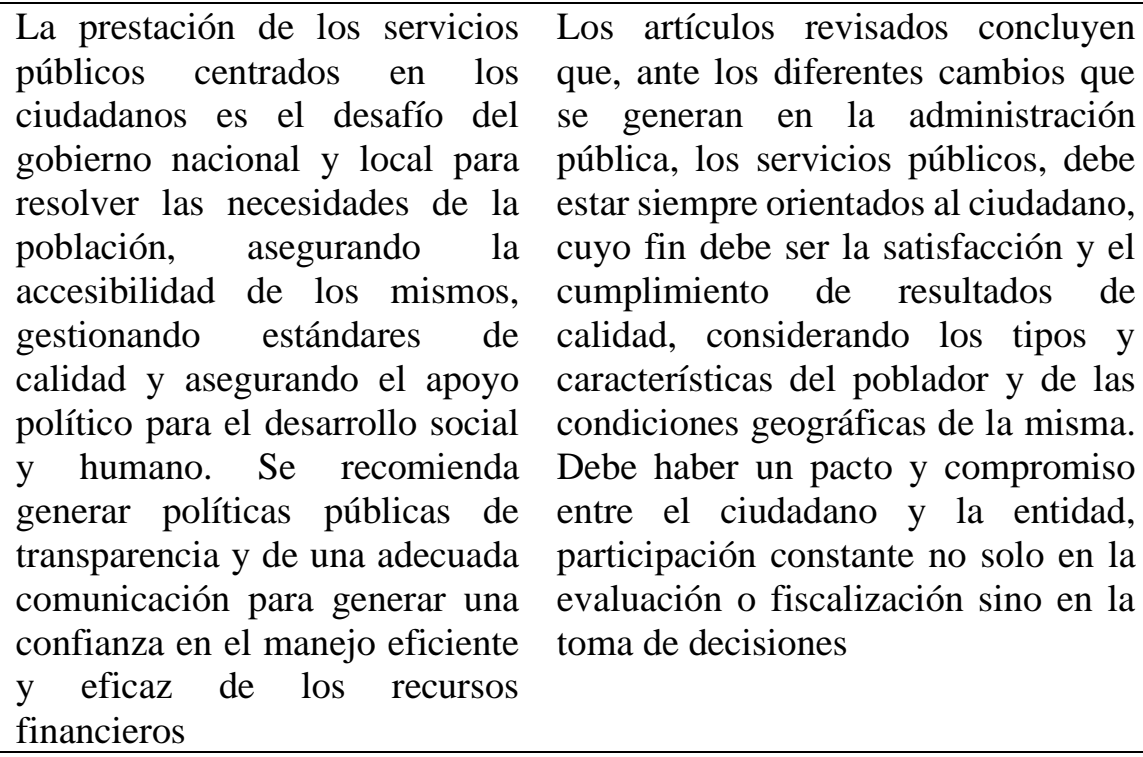 \\
\hline
\end{tabular}


DATOS DE LA PUBLICACIÓN

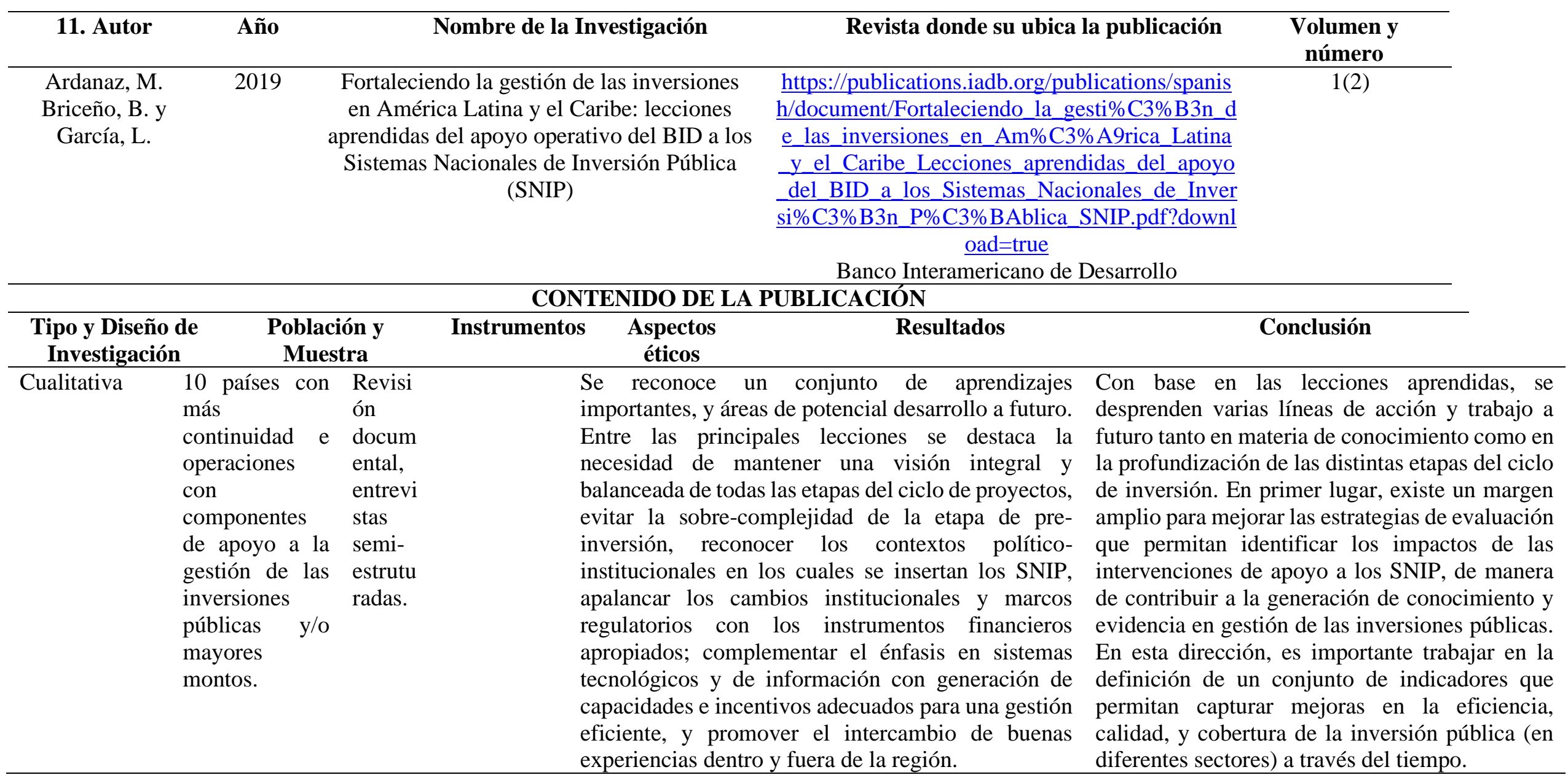

Ciencia Latina Revista Científica Multidisciplinar, Ciudad de México, México.

ISN 2707-2207 / ISSN 2707-2215 (en línea), noviembre-diciembre, 2021, Volumen 5, Número 6. https://doi.org/10.37811/cl rcm.v5i6.1110 p10704 


\section{DATOS DE LA PUBLICACIÓN}

\begin{tabular}{cccc}
\hline 12. Autor & Año & Nombre de la Investigación & Revista donde su ubica la publicación \\
\hline Córdova- & 2020 & Análisis de la recaudación de patentes municipales y plan de & https://dominiodelasciencias.com/ojs/ind \\
Cárdenas, E.L. & & mejora para el GAD Intercultural del Cantón Cañar & ex.php/es/article/view/1147/pdf \\
Narváez-Zurita, & & & $\begin{array}{c}\text { Dominio de las ciencias, revista } \\
\text { científica }\end{array}$ \\
C. y Erazo- & & & \\
Álvarez, J. & & & \\
\hline
\end{tabular}

\section{CONTENIDO DE LA PUBLICACIÓN}

\begin{tabular}{|c|c|c|c|c|c|c|}
\hline $\begin{array}{l}\text { Tipo y Diseño de } \\
\text { Investigación }\end{array}$ & $\begin{array}{c}\text { Población y } \\
\text { Muestra }\end{array}$ & Instrumentos & & $\begin{array}{l}\text { Aspectos } \\
\text { éticos }\end{array}$ & Resultados & Conclusión \\
\hline Mixto & 182 contribuyentes & $\begin{array}{l}\text { Encuesta } \\
\text { entrevista }\end{array}$ & $\mathrm{y}$ & 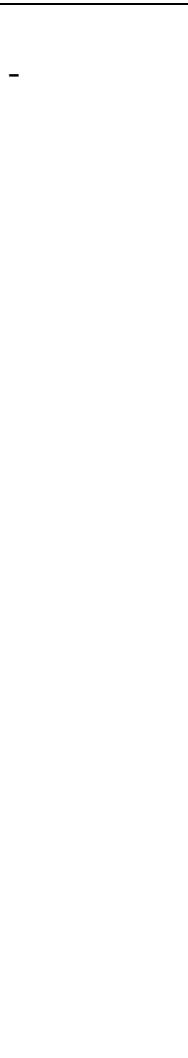 & $\begin{array}{l}\text { Es indispensable } \\
\text { implementación de estrategias } \\
\text { como son la habilitación de } \\
\text { plataformas tecnológicas que } \\
\text { preste las facilidades a los } \\
\text { contribuyentes para conocer sobre } \\
\text { el impuesto a la patente municipal } \\
\text { obteniendo como resultado la } \\
\text { concientización de los } \\
\text { contribuyentes } \\
\text { conjuntamente con un sistema } \\
\text { eficiente de catastro de dicho } \\
\text { impuesto siendo para } \\
\text { imprescindible la } \\
\text { determinación del impuesto y } \\
\text { como consecuencia conseguir la } \\
\text { optimización y presencia } \\
\text { predominante de la cultura } \\
\text { tributaria reflejada en el momento } \\
\text { de la cancelación de las obligaciones } \\
\text { la como contribuyentes y por ende la } \\
\text { reducción de la cartera vencida } \\
\text { mediante la recaudación óptima. }\end{array}$ & $\begin{array}{l}\text { Como resultado de la investigación se estableció que } \\
\text { COOTAD, es un cuerpo jurídico que ineludiblemente debe } \\
\text { aplicado por todos los GADS; en tal sentido, los municipi } \\
\text { mediante la obtención de ingresos por concepto de impuest } \\
\text { tasas y contribución especial de mejoras, así como ingresos } \\
\text { tributarios, solventaran las necesidades de sus habitantes y, p } \\
\text { consiguiente, recibirán los beneficios fruto de la eficacia con } \\
\text { que manejen los recursos. Existe desconocimiento del tribut } \\
\text { la patente municipal el cual debe pagar cada contribuyente q } \\
\text { posee una actividad económica dentro del cantón, esto se de } \\
\text { a que no ha existido información pertinente predominando } \\
\text { el desconocimiento para que los contribuyentes puedan cump } \\
\text { con sus pagos en forma } \\
\text { oportuna y adecuada. }\end{array}$ \\
\hline
\end{tabular}


DATOS DE LA PUBLICACIÓN

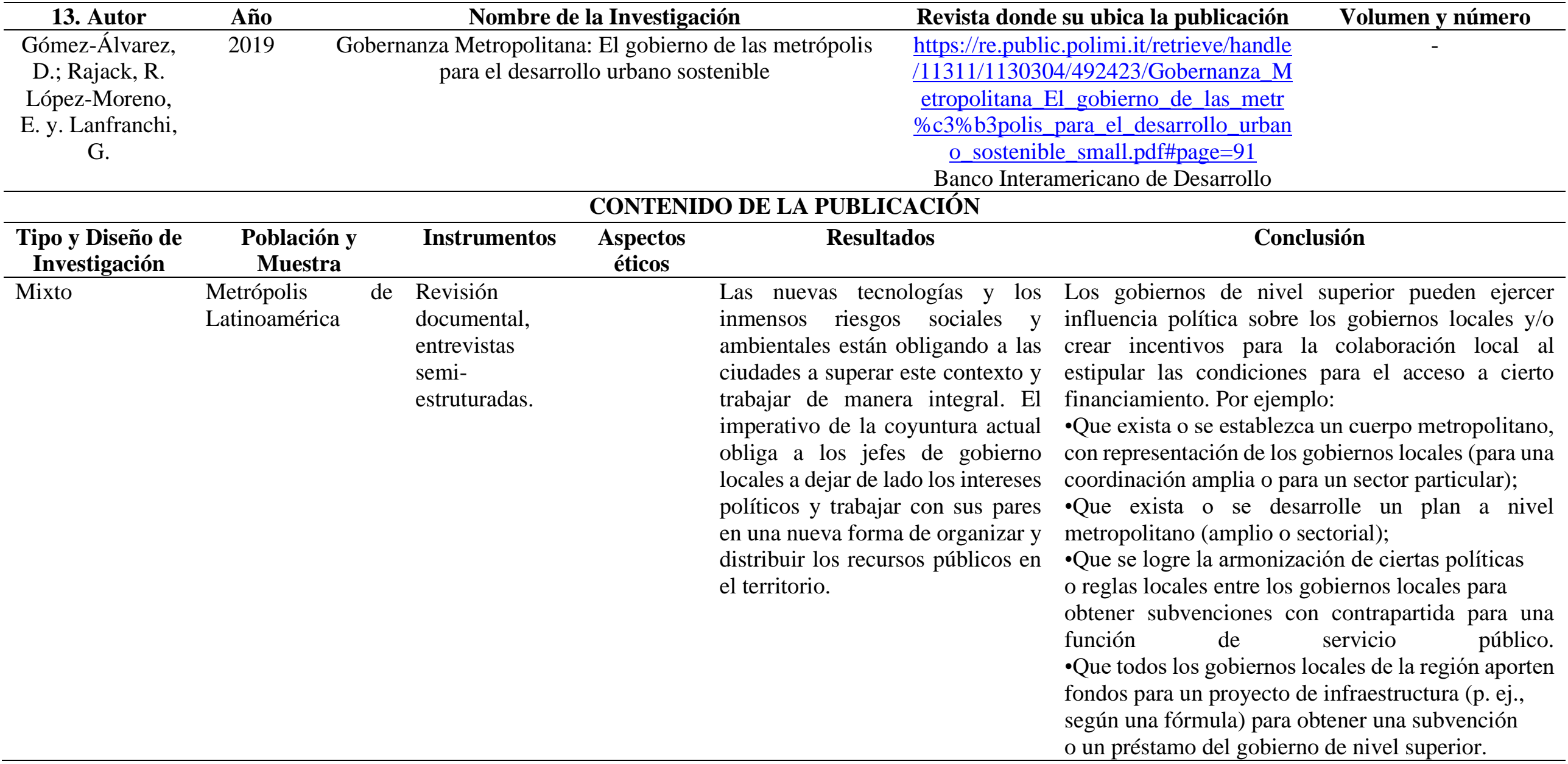

Ciencia Latina Revista Científica Multidisciplinar, Ciudad de México, México.

ISN 2707-2207 / ISSN 2707-2215 (en línea), noviembre-diciembre, 2021, Volumen 5, Número 6. https://doi.org/10.37811/cl rcm.v5i6.1110 p10706 


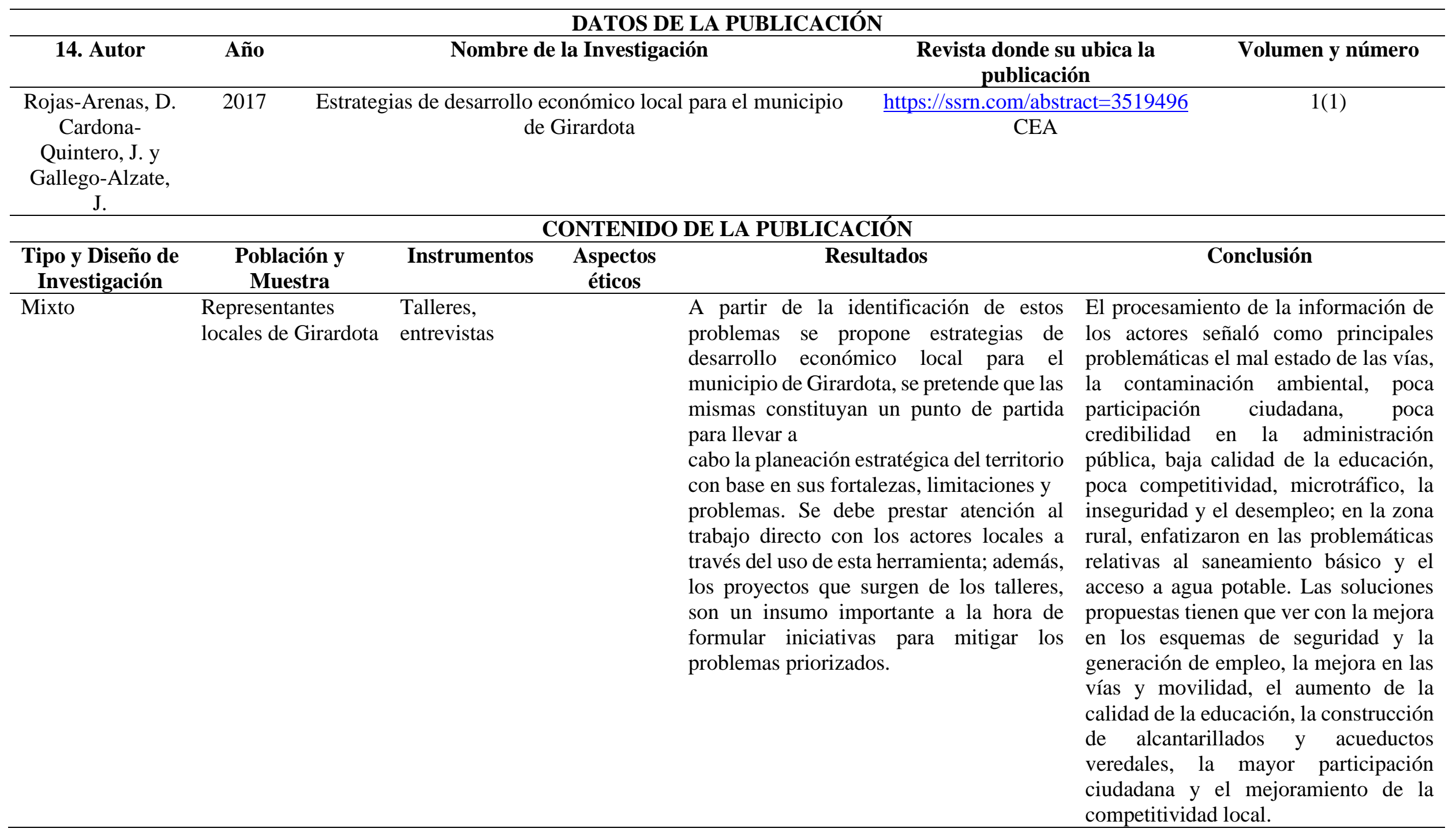


1.2. Estudios sobre plan de incentivos y gestión municipal

DATOS DE LA PUBLICACIÓN

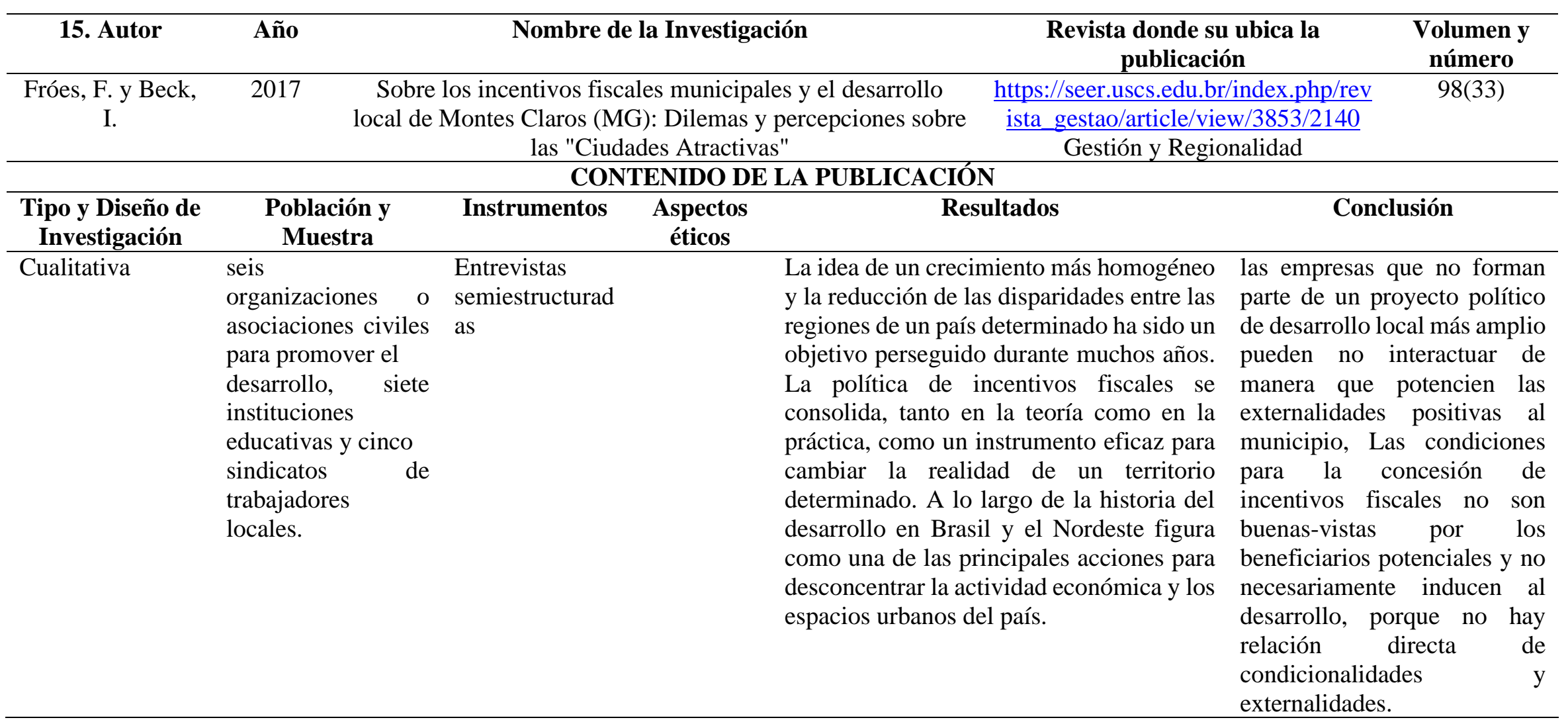

Ciencia Latina Revista Científica Multidisciplinar, Ciudad de México, México.

ISN 2707-2207 / ISSN 2707-2215 (en línea), noviembre-diciembre, 2021, Volumen 5, Número 6. https://doi.org/10.37811/cl rcm.v5i6.1110 p10708 


\begin{tabular}{|c|c|c|c|c|c|}
\hline \multicolumn{6}{|c|}{ DATOS DE LA PUBLICACIÓN } \\
\hline 16. Autor & Año & \multicolumn{2}{|c|}{ Nombre de la Investigación } & $\begin{array}{c}\text { Revista donde su ubica la } \\
\text { publicación }\end{array}$ & $\begin{array}{l}\text { Volumen y } \\
\text { número }\end{array}$ \\
\hline García, B. & Propu & \multicolumn{2}{|c|}{$\begin{array}{l}\text { Propuesta de indicador de eficiencia de la gestión pública } \\
\text { municipal en la promoción desarrollo local }\end{array}$} & $\begin{array}{c}\text { https://www.scielo.br/j/inter/a/7RpD } \\
\text { q3gz7QxV5bz4gW78Nrr/?lang=pt\& } \\
\text { format=pdf } \\
\text { INTERAÇÕES }\end{array}$ & $3(20)$ \\
\hline \multicolumn{6}{|c|}{ CONTENIDO DE LA PUBLICACIÓN } \\
\hline $\begin{array}{l}\text { Tipo y Diseño de } \\
\text { Investigación }\end{array}$ & $\begin{array}{l}\text { Población y } \\
\text { Muestra }\end{array}$ & Instrumentos & \multicolumn{2}{|c|}{ Resultados } & Conclusión \\
\hline Cuantitativo & $\begin{array}{l}29 \text { municipios de } \\
\text { Sao Pablo }\end{array}$ & $\begin{array}{l}\text { Análisis } \\
\text { envolvente de } \\
\text { datos (DEA) }\end{array}$ & $\begin{array}{l}\text { En total, se enc } \\
\text { eficientes simult } \\
\text { dimensiones de } \\
\text { En este aspecto } \\
\text { Mesorregión de } \\
\text { municipios beno } \\
\text { están en esta me } \\
\text { que emana del e } \\
\text { municipios limítr } \\
\text { escala del Loc } \\
\text { político municipa }\end{array}$ & $\begin{aligned} \text { ntraron 29 municipios } & \text { Se sugiere } \\
\text { eamente en todas las } & \text { futuro investi } \\
\text { arrollo local evaluadas. } & \text { los } 29 \text { munici } \\
\text { hay destaque para la } & \text { como eficient } \\
\text { ampinas. Entre los 29 } & \text { dimensiones. } \\
\text { marking general 28\% } & \text { diferencia de } \\
\text { rregión. Otro resultado } & \text { ser útil para } \\
\text { udio es la presencia de } & \text { públicas qu } \\
\text { es, corroborando que la } & \text { eficiencia y e } \\
\text { sobrepasa el límite } & \text { público. Ader } \\
& \text { sugiere uti } \\
& \text { paramétricas } \\
& \text { extrapolación }\end{aligned}$ & $\begin{array}{l}\text { omo estudio } \\
\text { r más a fondo } \\
\text { os clasificados } \\
\text { en las cuatro } \\
\text { atender qué la } \\
\text { demás puede } \\
\text { rear políticas } \\
\text { valoren la } \\
\text { uso del dinero } \\
\text { s, se } \\
\text { ar técnicas } \\
\text { le permitan la } \\
\text { datos. }\end{array}$ \\
\hline
\end{tabular}




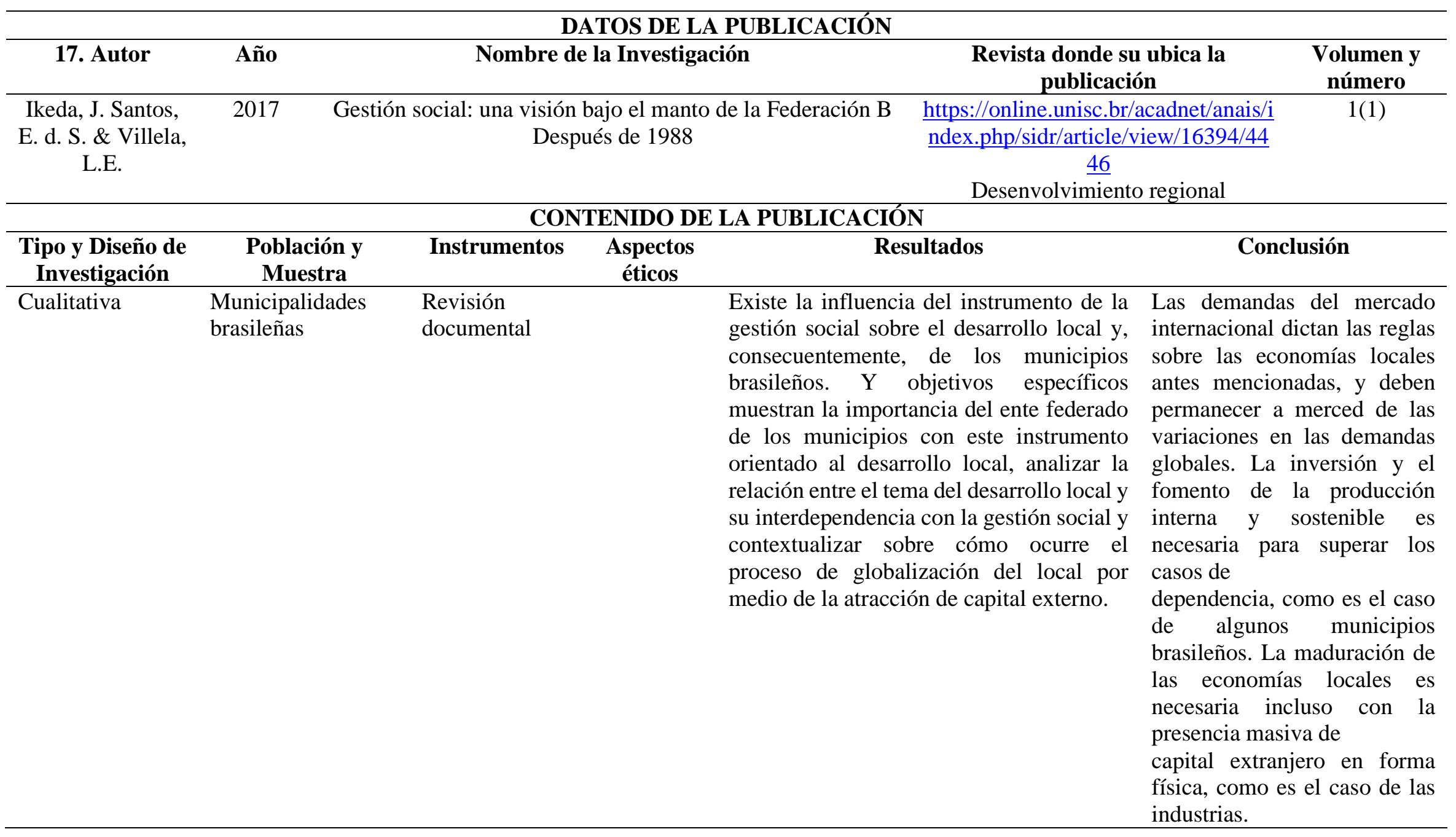

Ciencia Latina Revista Científica Multidisciplinar, Ciudad de México, México.

ISN 2707-2207 / ISSN 2707-2215 (en línea), noviembre-diciembre, 2021, Volumen 5, Número 6. https://doi.org/10.37811/cl rcm.v5i6.1110 p10710 


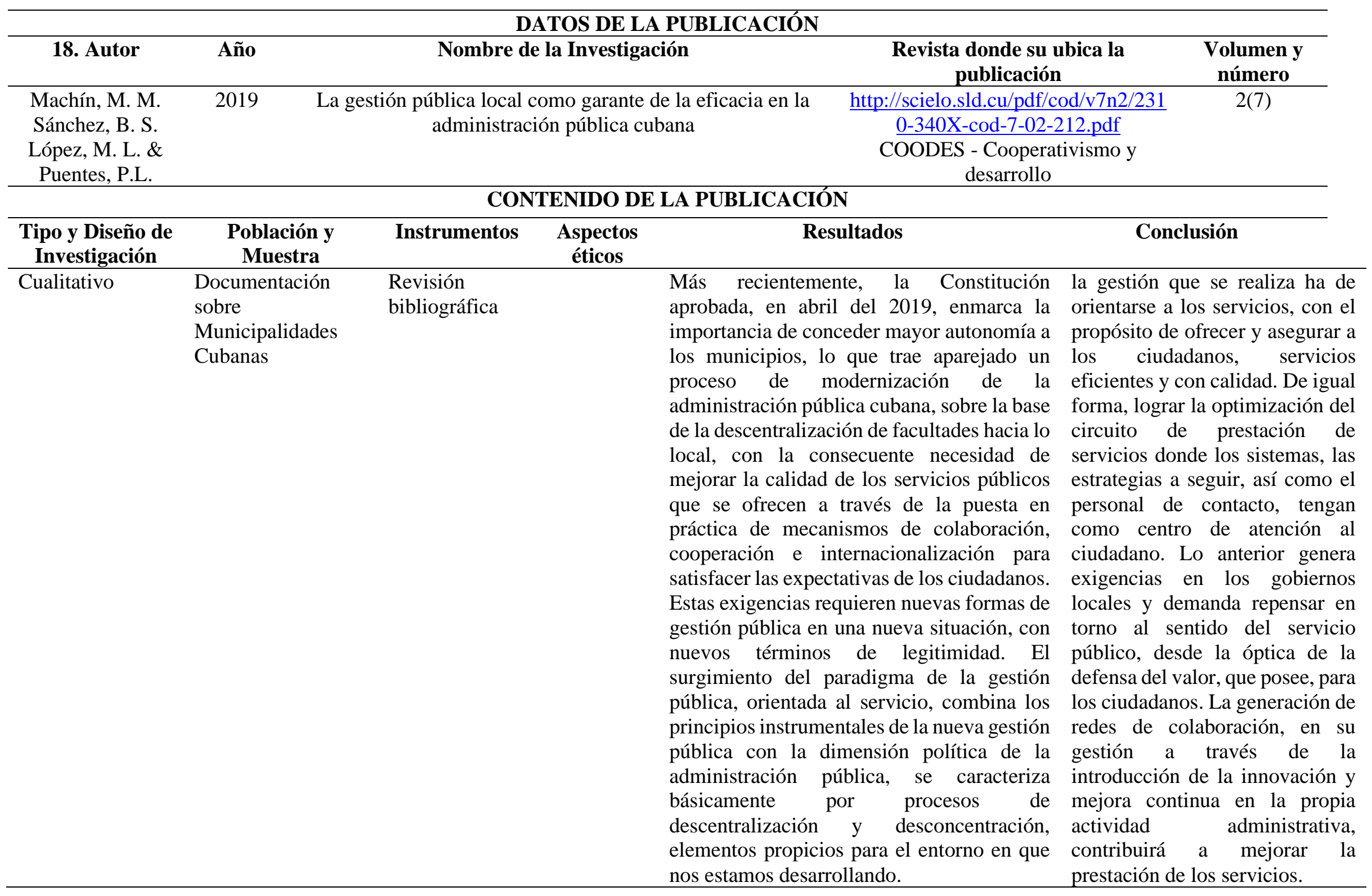




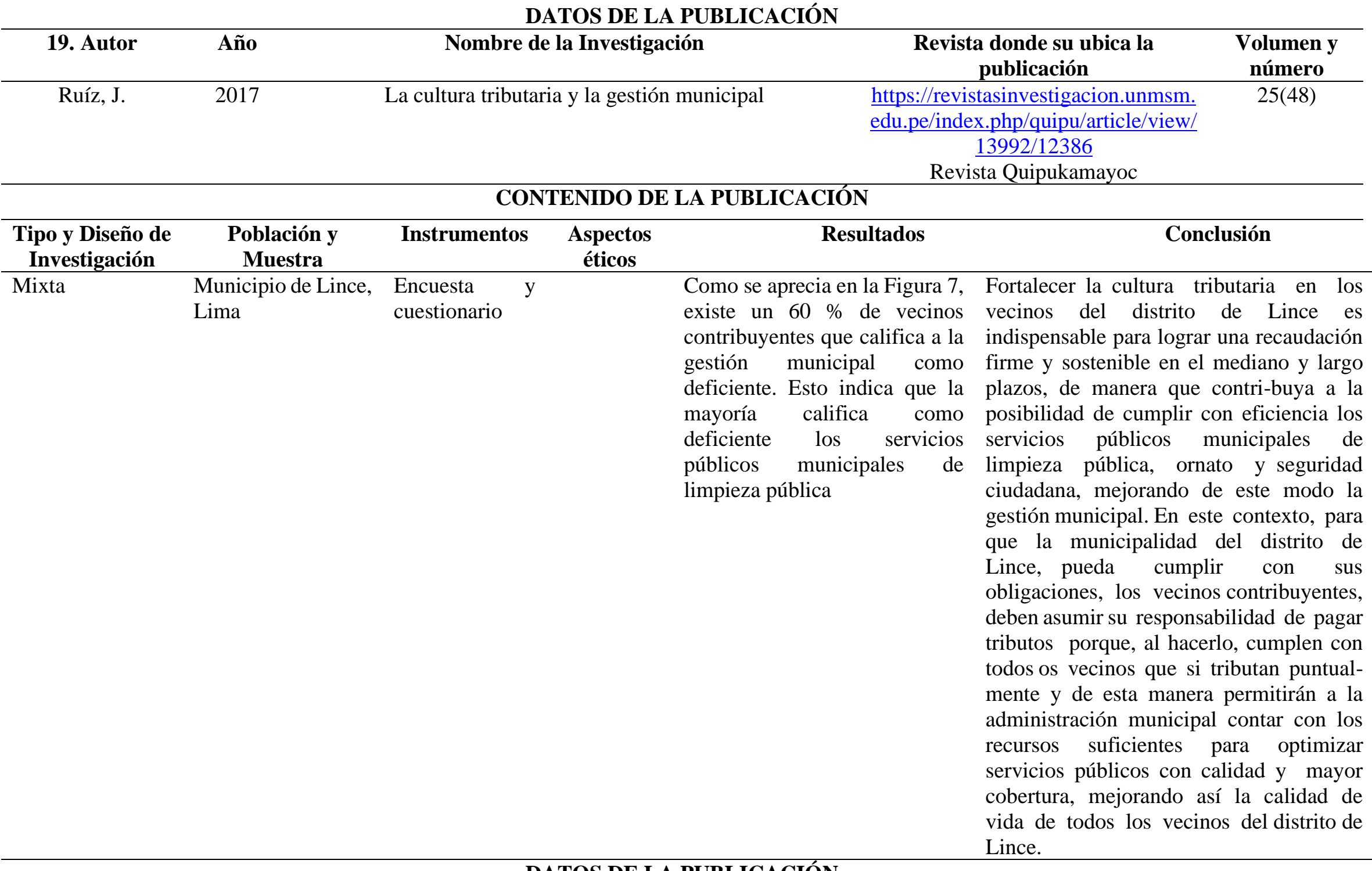

\section{DATOS DE LA PUBLICACIÓN}




\begin{tabular}{|c|c|c|c|c|}
\hline 20. Autor & Año & Nombre de la Investigación & $\begin{array}{c}\text { Revista donde su ubica la } \\
\text { publicación }\end{array}$ & $\begin{array}{c}\text { Volumen y } \\
\text { número }\end{array}$ \\
\hline $\begin{array}{c}\text { De Abreu, W. M. } \\
\text { Correa, R. } \\
\text { Cerqueira, D. } \\
\text { Matias-Pereira, J. } \\
\text { Barreto, F.J. }\end{array}$ & 2017 & $\begin{array}{c}\text { ¿La participación política y la gestión fiscal explican el } \\
\text { desarrollo social en Municipios brasileños? }\end{array}$ & $\begin{array}{l}\frac{\text { https://revista.enap.gov.br/index.php/ }}{\text { RSP/article/view/1429 }} \\
\text { Revista Servidores Brasilia Pública }\end{array}$ & $1(70)$ \\
\hline
\end{tabular}

Barreto, FJ.

\begin{tabular}{|c|c|c|c|c|}
\hline \multicolumn{5}{|c|}{ CONTENIDO DE LA PUBLICACIÓN } \\
\hline $\begin{array}{l}\text { Tipo y Diseño de } \\
\text { Investigación }\end{array}$ & $\begin{array}{l}\text { Población y } \\
\text { Muestra }\end{array}$ & Instrumentos & $\begin{array}{c}\text { Aspectos } \\
\text { éticos }\end{array}$ & Resultados \\
\hline Cuantitativo & $\begin{array}{c}\text { Municipalidades } \\
\text { brasileñas }\end{array}$ & Aex post facto & & $\begin{array}{c}\text { Se puede encontrar evidencia empírica } \\
\text { que valida la existencia de una relación } \\
\text { positiva entre desarrollo social y } \\
\text { participación política y gestión fiscal. } \\
\text { Luego de la adición de la variable de } \\
\text { control relacionada con el tema regional, } \\
\text { se identificó la ocurrencia de ganancias } \\
\text { significativas en la explicación del } \\
\text { modelo en estudio. Así, parece que las } \\
\text { políticas públicas que promueven el } \\
\text { desarrollo social, especialmente las } \\
\text { relacionadas con los incentivos a la } \\
\text { participación política y la gestión fiscal, } \\
\text { necesitan ser impulsadas más en los } \\
\text { municipios de unas regiones que en otras, } \\
\text { como una forma de incentivar la equidad } \\
\text { regional y la justicia social. }\end{array}$ \\
\hline
\end{tabular}




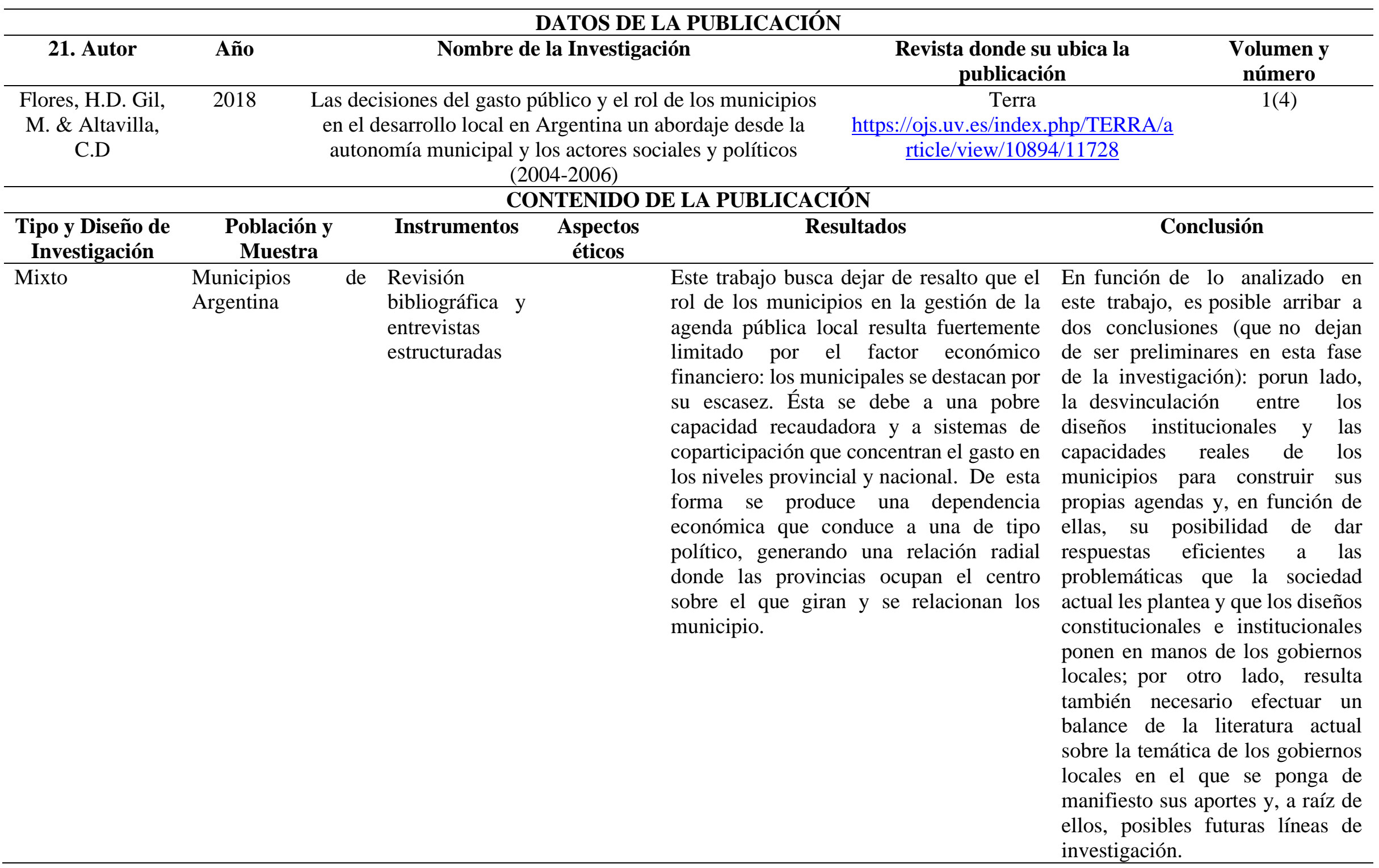

Ciencia Latina Revista Científica Multidisciplinar, Ciudad de México, México.

ISN 2707-2207 / ISSN 2707-2215 (en línea), noviembre-diciembre, 2021, Volumen 5, Número 6. https://doi.org/10.37811/cl rcm.v5i6.1110 p10714 


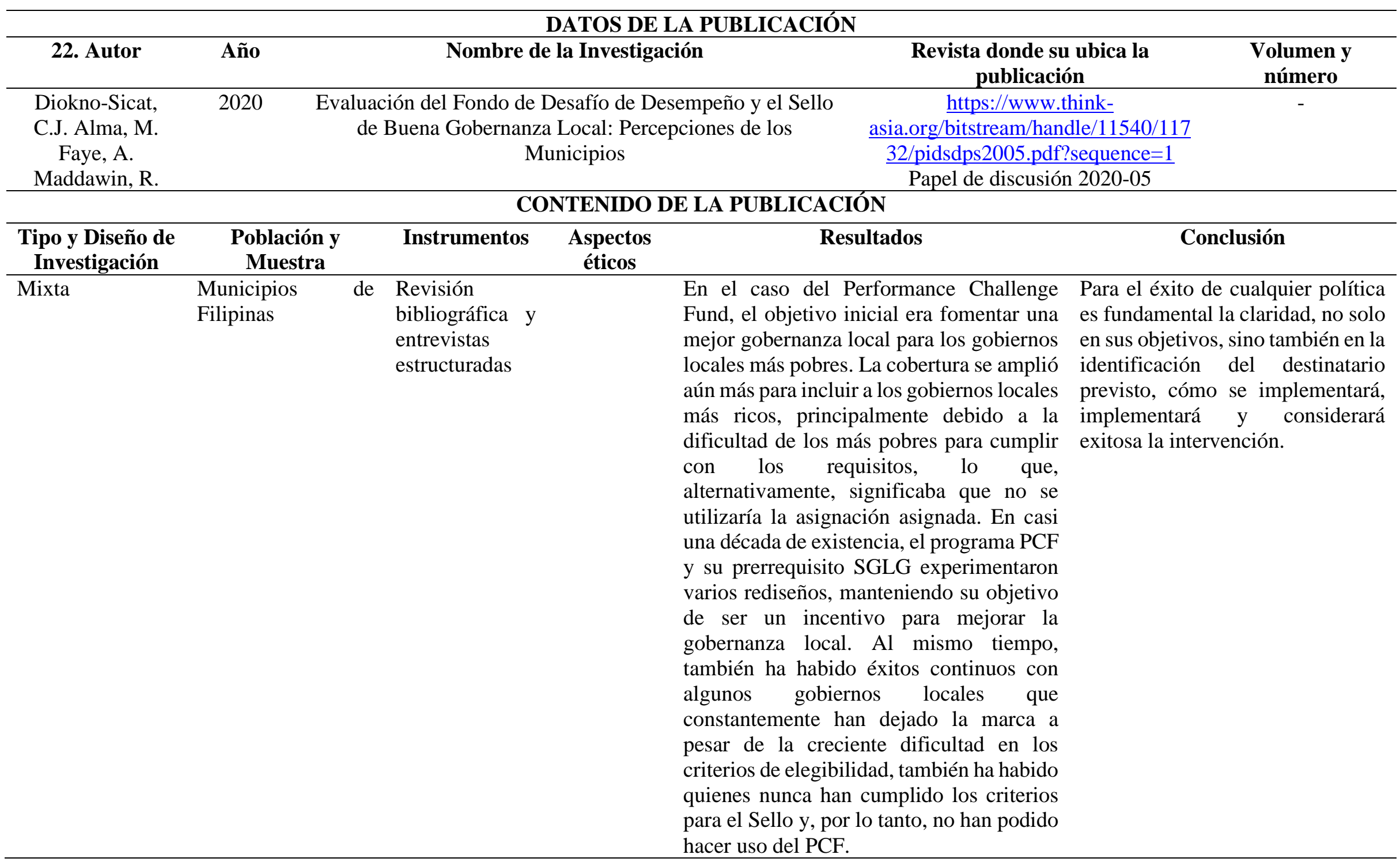




\section{DISCUSIÓN}

Después de ser revisados distintos buscadores, hay una cuestión que llama la atención. Se encuentran muchas fuentes relacionadas a las variables en cuestión si hablamos de tesis. Los repositorios, a pesar que, no con las variables mencionadas de manera exacta, contienen notorios trabajos relacionados al Plan de Incentivos, además de cómo se desarrolla la Gestión Municipal gracias al presupuesto por resultados. Por otro lado, en materia de revistas indexadas, el tema de incentivos es mayormente tomado por el lado de incentivos hacia los funcionarios públicos para aumentar la productividad en el servicio público, o, también, el tema en su auge, el tema de los incentivos ambientales para reducir los residuos sólidos.

El Plan de Incentivos para la mejora de gestión municipal es un tema popular para las investigaciones de grado en universitarios establecidos dentro de la administración y contabilidad, pero no se han publicado suficientes artículos científicos relacionados, en específico, a la problemática planteada de cómo el plan de incentivos contribuye en la gestión municipal. Aun así, se encontraron 22 artículos que tratan y/o se acercan a responder la pregunta planteada.

El Plan de Incentivos Integral se considera parte de los ejes de modernización de la gestión municipal. En Argentina, en la actualidad como Perú y otros países Latinoamericanos, dentro de su gestión saben lo importante que es la modernización de la gestión pública. Se ha tornado imprescindible la aplicación de herramientas de modernización en los municipios argentinos, haciendo referencia a dos grandes líneas estratégicas de gestión: las transformaciones institucionales, que implican llevar a cabo cambios orientados a incrementar la productividad y mejorar la calidad de los servicios prestados, involucrando por igual a los empleados públicos y a ciudadanos, y las transformaciones transversales, destinadas a optimizar y consolidar los sistemas horizontales (que incluye la gestión del capital humano, los sistemas de compras y contrataciones y de administración financiera, y el gobierno electrónico), aquí está implícito el presupuesto por resultados, adaptado al Plan de Incentivos (Pared y Zelaya, 2020).

En el caso boliviano, se encuentra el resultado de Jiménez (2017), quien menciona que queda pendiente dentro de la agenda, las intenciones de desarrollo local. Se requiere fortalecer a los gobiernos municipales, especialmente aquellos que están lisiados de las áreas metropolitanas y tienen menor capacidad para llevar a cabo y promover proyectos de desarrollo social, al igual que en la situación de varios gobiernos locales de nuestro país. La función que se realiza a nivel central es un inicio, pero requiere un mayor impulso en el uso de herramientas y la 
modernización de la gestión pública, un plan de incentivos más accesibles a esas localidades donde el cumplimiento de metas se hace dificultoso, debería recibir mejor coordinación, pues, el apoyo a la gobernanza municipal es fundamental para llevar a cabo programas de desarrollo local. Cuando comience el flujo del manejo del Plan de Incentivos hacia la gestión municipal de un gobierno local en particular, se observarán mejoras en un círculo vicioso de beneficio. No basta con que los municipios cuenten con los recursos necesarios para implementar las políticas públicas que ahora tienen a su cargo, sino que resulta necesario también que cuenten con una estructura y una organización adecuada para llevar adelante tales políticas de la manera más efectiva y eficiente posible. El legislador argentino se ha concentrado más en regular un régimen municipal genérico y abstracto y menos en propiciar instancias de colaboración mutua entre niveles de gobierno que permitieran construir agendas en función de las necesidades concretas de cada ente local, de acuerdo al contexto local, provincial y nacional (Flores, et al., 2017).

En La Libertad, Vargas (2020), menciona que en términos de cobertura se ha logrado un avance significativo en la implementación de los principales instrumentos de la reforma, pero su incidencia para orientar el proceso presupuestario hacia un enfoque por resultados es limitada. Los programas presupuestales, y el seguimiento de su desempeño, presentan deficiencias en su implementación y no cuentan con mecanismos efectivos para utilizar de manera sistemática la información de desempeño en el proceso presupuestario.

Los estudios relacionados a la evaluación según modernización del Estado reconocen las bondades y beneficios en el contexto de la gestión púbica, debido a que la evaluación demanda compromiso institucional, políticas, condiciones y consecuencias; y se puede establecer que la evaluación tiene un impacto en la gestión lógicamente distinta en diferentes países del mundo (Seminario y Delgado, 2020).

La implementación de las políticas públicas es un proceso complejo y de participación de diversos actores a lo largo de toda su cadena de diseño y ejecución. Durante dicho recorrido se presentan diversos déficits o variaciones podrían afectar a las políticas públicas en sí. Para Tejada (2021), es importante establecer mecanismos de seguimiento y control; también es conveniente poder mantener la correcta ejecución y evitar distorsiones a lo largo de todo su funcionamiento a través de incentivos, y evitar la intromisión de intereses particulares o de sabotaje. El Plan de Incentivos tiene un esquema de paso a seguir para poder recibir la transferencia hacia el municipio participante y ganador, por lo que un importantes seguimiento, control y evaluación va a influir en que este mecanismo de modernización siga 
beneficiando al desarrollo de una municipalidad distrital del país.

La evaluación también permite determinar las capacidades y competencias desarrolladas en el recurso humano para que tome un camino diferente a favor del desarrollo institucional asegurando la vida sostenible a pesar de la crisis económica de los países, porque hay acciones que no depende de dinero sino del comportamiento de los colaboradores. El liderazgo y el trabajo en equipo multidisciplinario y multisectorial es la herramienta de cambio para la mejorar la evaluación en la gestión pública y garantizar un desarrollo sostenible para las nuevas generaciones (Seminario y Delgado, 2020).

Esto indica que la gestión que se realiza ha de orientarse a los servicios, con el propósito de ofrecer y asegurar a los ciudadanos, servicios eficientes y con calidad. De igual forma, lograr la optimización del circuito de prestación de servicios donde los sistemas, las estrategias a seguir, así como el personal de contacto, tengan como centro de atención al ciudadano. Lo anterior genera exigencias en los gobiernos locales y demanda repensar en torno al sentido del servicio público, desde la óptica de la defensa del valor, que posee, para los ciudadanos. La generación de redes de colaboración, en su gestión a través de la introducción de la innovación y mejora continua en la propia actividad administrativa, contribuirá a mejorar la prestación de los servicios (Machín, et al., 2019).

En la investigación de Gaviria y Delgado (2020), se demuestra en el análisis sistemático de los artículos científicos revisados por estos, que, del total revisado, el $46 \%$ corresponden a México y España, el 64\% a Perú, Colombia, Ecuador y Chile, la mayor parte de las conclusiones de los autores, coinciden en que una buena administración de los servicios públicos, debe estar centrado en las necesidades del ciudadano y que a la vez se refleje en la satisfacción de la misma. Debe haber un pacto y compromiso entre el ciudadano y la entidad, participación constante no solo en la evaluación o fiscalización sino en la toma de decisiones. Es importante que no solo se tome importancia en la parte fiscal, sino, en la parte de la gestión humana, siendo dos ejes esenciales que permiten al Plan de incentivos transformar la gestión municipal con el compromiso institucional de los servidores públicos.

Es por eso que se debe evitar seguir recayendo en la falta de implementación de los programas de inversión de manera oportuna, pues esto conduce a un retraso en el desarrollo de la economía local. Además, la evaluación actual se basa en la presencia y ausencia de determinados requisitos, por lo que los esfuerzos deberían centrarse ahora en la evaluación en profundidad de los planes presentados (Diokno-Sicat, et al., 2020). 


\section{CONCLUSIONES Y RECOMENDACIONES}

Se determina que, durante la revisión de artículos, existieron investigaciones tanto cualitativas como cuantitativas, hasta de carácter mixto. Diferentes disciplinas dan importancia a la gestión municipal y a su mejoramiento para el desarrollo local. Los países donde se visualiza la preocupación de avanzar en esta materia son principalmente, latinoamericanos.

En cuanto a investigaciones europeas o filipinas, dan importancia a un contexto más allá de la gestión municipal, intentando enlazarla en distintos aspectos culturales o industriales, por lo que falta un largo camino a recorrer para poder salir más allá de la problemática de un lento proceso de modernización en gestión municipal.

El Plan de Incentivos Integral ayuda a la gestión municipal a desarrollarse, pero no es su sola aplicación la que cumplirá con todas las deficiencias que se tienen actualmente, el compromiso de los funcionarios púbicos para el cumplimiento de metas y la permanencia de un buen servicio público será el incentivo para impulsar a que esta gestión pueda llegar al siguiente nivel. Por otro lado, se debe mantener un constante interés y estar capacitado para coordinar y cumplir las metas correspondientes al PI con tal de seguir recibiendo este incentivo.

Es obvia la necesidad y se recomienda una capacitación en cuanto al PI y a los presupuestos por resultados, existe desconocimiento entre los funcionarios de las municipalidades que podrían cumplir las condiciones para recibir la transferencia, recordando que a pesar de que todas las municipalidades participan, no siempre existe la voluntad o el conocimiento de participar para recibir los incentivos.

Se rescata, entre los resultados de los artículos revisados, la preocupación del poco impulso de los gobiernos centrales hacia los gobiernos locales más pequeños. Está comprobada la eficacia del Plan de Incentivos para mejorar la gestión municipal, pero el hecho de que conseguir cumplir las metas establecidas tenga obstáculos de por medio, aleja la oportunidad de visualizar esta mejora, además, de la poca información académica existente, la realidad se reduce a casos particulares que no pueden dar una generalización adecuada del problema, por lo que se recomienda incentivar a los académicos de la gestión pública, investigar la eficiencia del Plan de Incentivos Integral dentro de la Gestión Municipal y si pueden acceder fácilmente a esta.

\section{REFERENCIAS}

Anastacio, C., García, A. y Mego, O. (2019). Gestión del talento humano por competencias y su relación con la motivación de los colaboradores de una Municipalidad de la Región 
Lambayeque,

Perú

2019. Tzhoecoen, 12(4),

$436-448$.

http://revistas.uss.edu.pe/index.php/tzh/article/view/1394/1928

Ardanaz, M., Briceño, B., y García, L. A. (2019). Fortaleciendo la gestión de las inversiones en América Latina y el Caribe: lecciones aprendidas del apoyo operativo del BID a los Sistemas Nacionales de Inversión Pública (SNIP). Banco Interamericano de Desarrollo, 1(1),

https://publications.iadb.org/publications/spanish/document/Fortaleciendo_la_gesti\%C3 \%B3n_de_las_inversiones_en_Am\%C3\%A9rica_Latina_y_el_Caribe_Lecciones_apren didas_del_apoyo_del_BID_a_los_Sistemas_Nacionales_de_Inversi\%C3\%B3n_P\%C3 \%BAblica_SNIP.pdf?download=true

Arévalo, R. Ortuño, G. y Arévalo, D. (2010). Revisiones sistemáticas (1). Revista Médica La Paz, 16(2), 69-80. Recuperado en 19 de agosto de 2021, de http://www.scielo.org.bo/scielo.php?script=sci_arttext\&pid=S1726$\underline{89582010000200012 \& \operatorname{lng}=e s \& t \operatorname{lng}=e s}$.

Cobeña, X. (2017). Evolución De Las Finanzas Municipales En La Provincia De Manabí Y La Contribución Del Modelo De Equidad Territorial. Sinergia,6(6), 5-17. https://dialnet.unirioja.es/descarga/articulo/6197619.pdf

Cordero, J. (2018). El gobierno municipal. ¿Promotor del desarrollo local? El caso del municipio semiurbano de $\mathrm{Cd}$. Ixtepec, Oaxaca. Estudios sociales. Revista de alimentación contemporánea $y$ desarrollo regional, 28(52)https://doi.org/10.24836/es.v28i52.575

Córdova-, E. L., Narváez, C. y Erazo, J. (2020). Análisis de la recaudación de patentes municipales y plan de mejora para el GAD Intercultural del Cantón Cañar. Dominio de las ciencias, $\quad$ Revista científica, 6(1), 224-251. https://dominiodelasciencias.com/ojs/index.php/es/article/view/1147/pdf

De Abreu, W., Correa, R., Cerqueira, D., Matias, J. y Barreto, F. (2017). ¿La participación política y la gestión fiscal explican el desarrollo social en Municipios brasileños? Revista Servidores Brasilia Pública, 70(1), 83-102. https://doi.org/10.21874/rsp.v70i1.1429

Delgado, J. (2020). Mejora de los servicios públicos en el fortalecimiento de la gestión municipal. Ciencia Latina Revista Científica Multidisciplinar,4(2), 1241-1255. https://www.ciencialatina.org/index.php/cienciala/article/view/151/182

Díaz, M. y Fernández, A. (2020). Gestión de gobierno, educación superior, ciencia, innovación y desarrollo local. Retos de la Dirección, 14(2), 5-32. 
http://scielo.sld.cu/scielo.php?script=sci_arttext\&pid=S2306-

\section{5\&lng=es\&tlng=es}

Diokno-Sicat, C. J., Alma, M., Faye, A., y Maddawin, R. (2020). Evaluación del Fondo de Desafío de Desempeño y el Sello de Buena Gobernanza Local: Percepciones de los Municipios. Papel de discusión 2020-05, 1-64. https://www.thinkasia.org/bitstream/handle/11540/11732/pidsdps2005.pdf?sequence=1

Escobedo, C. (2019). Importancia del programa de incentivos a la mejora de la gestión municipal en el servicio de seguridad ciudadana en los gobiernos locales en el Perú [Universidad Católica San Pablo]. https://repositorio.ucsp.edu.pe/bitstream/UCSP/16026/1/ESCOBEDO_PINTO_CHR_I NC.pdf

Flores, H., Gil, M., y Altavilla, C. (2018). Las decisiones del gasto público y el rol de los municipios en el desarrollo local en Argentina un abordaje desde la autonomía municipal y los actores sociales y políticos (2004-2006). Terra, Revista de desarrollo local, 4(1), 131. https://ojs.uv.es/index.php/TERRA/article/view/10894/11728

Fróes, F., y Beck, I. (2017). Sobre los incentivos fiscales municipales y el desarrollo local de Montes Claros (MG): Dilemas y percepciones sobre las "Ciudades Atractivas". Gestión $y$

$$
\text { Regionalidad, 33(98), }
$$

https://seer.uscs.edu.br/index.php/revista_gestao/article/view/3853/2140

García, B. (2019). Propuesta de indicador de eficiencia de la gestión pública municipal en la promoción desarrollo local. INTERAÇÕES, 20(3), 815-830. https://www.scielo.br/j/inter/a/7RpDq3gz7QxV5bz4gW78Nrr/?lang=pt\&format=pdf

García, I. (2007). La nueva gestión pública: evolución y tendencias. España; Universidad de Salamanca.

https://www2.congreso.gob.pe/sicr/cendocbib/con4_uibd.nsf/B1168625381F1AE70525 7BCA00165978/\$FILE/47_GarciaSanchez.pdf

Gómez, D., Rajack, R. López, E. y Lanfranchi, G. (2019). Gobernanza Metropolitana: El gobierno de las metrópolis para el desarrollo urbano sostenible. BID, 1(1), 1-129. https://re.public.polimi.it/retrieve/handle/11311/1130304/492423/Gobernanza_Metropol itana_El_gobierno_de_las_metr\%c3\%b3polis_para_el_desarrollo_urbano_sostenible_s mall.pdf\#page $=91$

Gómez, R. Morales, R., y Rodríguez, C. (2017). La Economía del Bien Común en el ámbito local. CIRIEC-España, Revista de Economía Pública, Social y Cooperativa, 90(1), 189- 
222. https://www.redalyc.org/pdf/174/17452685007.pdf

Hernández, S. Fernández, C. y Baptista, P. (2014). Metodología de la investigación. 6ta Edición. Mc Graw Hill Education. https://www.uca.ac.cr/wpcontent/uploads/2017/10/Investigacion.pdf

Hurtado, A. y Gonzales, E. (2015). La gestión y planificación municipal en el Perú. https://core.ac.uk/download/pdf/270318967.pdf

Ikeda, J. y Villela, L. (2017). Gestión social: una visión bajo el manto de la Federación B Después de 1988. Desenvolvimiento regional, 1(1), 1-12. https://online.unisc.br/acadnet/anais/index.php/sidr/article/view/16394/4446

Jiménez, W. (2017). Movilización de recursos domésticos, desarrollo social y cambio institucional: Descentralización y autonomías municipales en Bolivia. UNRISD Working Paper, 1, 1-19. https://www.econstor.eu/bitstream/10419/186089/1/1010303007.pdf

Machín, M., Sánchez, B., López, M., y Puentes, P. (2019). La gestión pública local como garante de la eficacia en la administración pública cubana. COODES - Cooperativismo y desarrollo, 7(2), 212-224. $\quad$ http://scielo.sld.cu/pdf/cod/v7n2/2310-340X-cod-7-02212.pdf

MEF. (2018). Marco Conceptual del Programa de Incentivos a la Mejora de la Gestión Municipal.

https://www.mef.gob.pe/contenidos/presu_publ/migl/pi/marco_conceptual_PI.pdf

OIT y MDG Achivement Fund (2017). Guía metodológica de planificación y gestión municipal de servicios de agua y saneamiento. OIT. https://www.sdgfund.org/sites/default/files/EDG_GUIA_\%20Honduras_Planificacion\% 20Y\%20Gestion\%20Municipal\%20de\%20AyS.pdf

Pared, A., y Zelaya, M. (2020). La innovación y el desarrollo local en el gobierno municipal Hacia un estado de situación actual en Argentina. Ec-Revista De Administración y Economía, 4(3), 59-70. https://publicaciones.unpaz.edu.ar/OJS/index.php/ec/

Papazoglou, G. (2019). Society and culture: Cultural policies driven by local authorities as A factor in local development - the example of the municipality of XanthiGreece. Heritage, 2(3), 2625-2639. https://www.mdpi.com/2571-9408/2/3/161/htm

Polanco, A. y Caballero, M. (2020). La gestión de la cultura en el desarrollo local. Aproximaciones desde el fortalecimiento de capacidades. Cuadernos Del Claeh, 39(111), 135-151. https://doi.org/10.29192/claeh.39.1.7

Rojas, D. Cardona, J. y Gallego, J. (2017). Estrategias de desarrollo económico local para el 
municipio de Girardota. Rojas-Arenas, D. Cardona-Quintero, J.A. Gallego-Alzate, J.B., 3(6), 29-45. https://ssrn.com/abstract=3519496

Rosales, M. (2016). Descentralización, municipios y modelos de gestión local en América Latina. En J. Maldonado (Ed.), Manual de Gestión Municipal (pp. 115-147). UMC. http://estudios.umc.cl/wp-content/uploads/2017/05/MANUAL-SERIE-7.pdf

Ruiz, J. (2017). La cultura tributaria y la gestión municipal. Revista Quipukamayoc, 48(25), 49-60. https://revistasinvestigacion.unmsm.edu.pe/index.php/quipu/article/view/13992/123 $\underline{86}$

Seminario, F., y Delgado, J. (2020). Ciencia Latina Revista Científica Multidisciplinar, 4(2), 914-935. https://ciencialatina.org/index.php/cienciala/article/view/131/112

Tejada, R. (2021). Incentivos intrínsecos al servidor público para una gestión por resultados eficiente. Saber Servir, 5(1), 76-92. http://revista.enap.edu.pe/article/view/4466/5033

Vargas, J. y Zavaleta, W. (2020). La gestión del presupuesto por resultados y la calidad del gasto en gobiernos locales. Visión de futuro, 24,2, 37-59. https://visiondefuturo.fce.unam.edu.ar/index.php/visiondefuturo/issue/view/18 